Article

\title{
Complete Chloroplast Genomes and Comparative Analysis of Sequences Evolution among Seven Aristolochia (Aristolochiaceae) Medicinal Species
}

\author{
Xiaoqin $\mathrm{Li}^{1,2,3}$, Yunjuan Zuo ${ }^{1}{ }^{\mathbb{D}}$, Xinxin Zhu ${ }^{4}$, Shuai Liao ${ }^{5}$ and Jinshuang Ma ${ }^{1, *}$ \\ 1 Shanghai Chenshan Plant Science Research Center, Chinese Academy of Sciences, Shanghai Chenshan \\ Botanical Garden, Shanghai 201602, China; lxq@sibs.ac.cn (X.L.); zuo.yunjuan@gmail.com (Y.Z.) \\ 2 Shanghai Center for Plant Stress Biology, Chinese Academy of Sciences, Shanghai 201602, China \\ 3 University of Chinese Academy of Sciences, Shanghai 201602, China \\ 4 College of Life Sciences, Xinyang Normal University, Xinyang 464000, Henan, China; \\ huamixinhua1@gmail.com \\ 5 School of Life Sciences, East China Normal University, Shanghai 200241,China; shuai_liao@bjfu.edu.cn \\ * Correspondence: jinshuangma@gmail.com; Tel.: 86-21-6765-7816
}

Received: 18 January 2019; Accepted: 21 February 2019; Published: 28 February 2019

\begin{abstract}
Aristolochiaceae, comprising about 600 species, is a unique plant family containing aristolochic acids (AAs). In this study, we sequenced seven species of Aristolochia, and retrieved eleven chloroplast (cp) genomes published for comparative genomics analysis and phylogenetic constructions. The results show that the cp genomes had a typical quadripartite structure with conserved genome arrangement and moderate divergence. The cp genomes range from 159,308 bp to $160,520 \mathrm{bp}$ in length and have a similar GC content of $38.5 \%-38.9 \%$. A total number of 113 genes were identified, including 79 protein-coding genes, 30 tRNAs and four rRNAs. Although genomic structure and size were highly conserved, the IR-SC boundary regions were variable between these seven cp genomes. The trnH-GUG genes, are one of major differences between the plastomes of the two subgenera Siphisia and Aristolochia. We analyzed the features of nucleotide substitutions, distribution of repeat sequences and simple sequences repeats (SSRs), positive selections in the cp genomes, and identified 16 hotspot regions for genomes divergence that could be utilized as potential markers for phylogeny reconstruction. Phylogenetic relationships of the family Aristolochiaceae inferred from the $18 \mathrm{cp}$ genome sequences were consistent and robust, using maximum parsimony (MP), maximum likelihood (ML), and Bayesian analysis (BI) methods.
\end{abstract}

Keywords: Aristolochia; chloroplast genome; molecular evolution; compare analysis; phylogeny

\section{Introduction}

Aristolochia sensu lato, comprising about 500 species, is the largest genus of Aristolochiaceae, with a broad distribution range from tropical to subtropical, extending to temperate regions $[1,2]$. Several species of Aristolochia, such as Aristolochia moupinensis, Aristolochia tagala, and Aristolochia mollissima, have been reported as traditional Chinese medicines [3,4]. Aristolochiaceae is a unique plant family containing aristolochic acids (AAs), and their derivatives are widely implicated in liver cancers $[5,6]$. However, current studies have demonstrated that AAs are of nephrotoxicity, carcinogenicity, and mutagenicity $[7,8]$. The sale and use of AA-containing herbal preparations have been restricted in many countries [9].

The monophyly of Aristolochiaceae was well supported in most analysis, and was divided into two subfamilies, Asaroideae and Aristolochioideae [10,11]. The studies recognized two genera Saruma and Asarum in Asaroideae [10-13]. The genus Aristolochia of subfamily Aristolochioideae 
was classified into two major lineages, as indicated by previous studies based on morphological characters and molecular phylogenetic methods $[10,14-16]$. In the past years, the nuclear ITS2, phyA gene, and several plastid genome regions (such as matk, $r b c L$, trnK, and $\operatorname{trnL}-\operatorname{trnF}$ ) or their combinations have been frequently used in molecular systematics of Aristolochiaceae $[11,15,17,18]$. The inter-simple sequence repeat (ISSR) markers were also used to identify diverse genetic stocks and understand the evolutionary relationships of Aristolochia $[19,20]$. The selected loci failed to provide sufficient phylogenetic information to elucidate the evolutionary relationships among Aristolochia species. A universal barcode either using whole chloroplast (cp) genomes or hyper-variable regions are urgently needed, which may significantly improve the low resolution in plant relationships and contribute to the conservation, domestication, and utilization of Aristolochia plants.

The chloroplast is the key organelle for photosynthesis and carbon fixation in green plants [21]. Their genomes could provide valuable information for taxonomic classification and phylogenetic reconstruction among species of land plants [22-25]. Typical cp genomes in angiosperms have a generally conserved quadripartite circular structure with two copies of inverted repeat (IR) regions that are separated by a large single copy (LSC) region and a small single copy (SSC) region, and encode $120-135$ genes with sizes in the range of $120-170 \mathrm{~kb}[26,27]$. In recent years, the $\mathrm{cp}$ genomes of Aristolochia debilis, Aristolochia contorta, Saruma henryi, and nine species of Asarum within the Aristolochiaceae family have been reported [28-31]. Those sequenced cp genomes of Aristolochiaceae, except for those of Asarum species, were conserved in length, gene and GC content, from which no rearrangement event had been detected.

With the rapid development of next-generation sequencing (NGS), it is now more convenient and cheaper to obtain cp genome sequences, feasible to compare analysis of sequences evolution among different individuals. In this study, we reported seven complete cp genomes of Aristolochia and conducted comparative genomic analyses, focused on gene size, content, patterns of nucleotide substitutions, and variable sites. Another 12 published $\mathrm{cp}$ genome sequences of Magnoliids downloaded from the National Center for Biotechnology Information (NCBI) organelle genome database (https: / / www.ncbi.nlm.nih.gov) [32] were also used to detect selective sites, repeat sequences, simple sequence repeats (SSRs), and phylogenetic constructions. We performed these comparative genomes analysis to obtain comprehensive understanding the structure of plastomes within Aristolochia and to provide genetic resources for future research in the genus.

\section{Results}

\subsection{The Chloroplast Genome Structures of Species}

All the species of Aristolochia we sequenced had a typical quadripartite structure, with a circular molecule of $159,308 \mathrm{bp}$ to $160,520 \mathrm{bp}$ in length. The complete cp genomes of involved species comprise an LSC region (88,652-89,859 bp) and an SSC region (19,322-19,799 bp), separated by a pair of IRs ranging from 25,242 bp to 25,700 bp in length (Figure 1, Table 1). GC content of the plastomes of the seven Aristolochia species varies slightly from $38.5 \%$ to $38.9 \%$ (Table 1). The GC content within coding sequence (CDS) of the two species (A. tagala and A. tubiflora) of subgenus Aristolochia and five species (A. kunmingensis, A. moupinensis, A. macrophylla, A. kaempferi, and A. mollissima) of subgenus Siphisia was $38.9 \%$ and $39.2 \%$, respectively. GC\% content of the first position was higher compared to those of the second and third positions (Figure 2, Table S1). A total of 113 unique genes were identified in the seven cp genomes, including 79 protein coding genes, 30 tRNAs and four rRNAs, 19 or 18 genes of which duplicated in the IR region (Tables 1 and 2). 
A

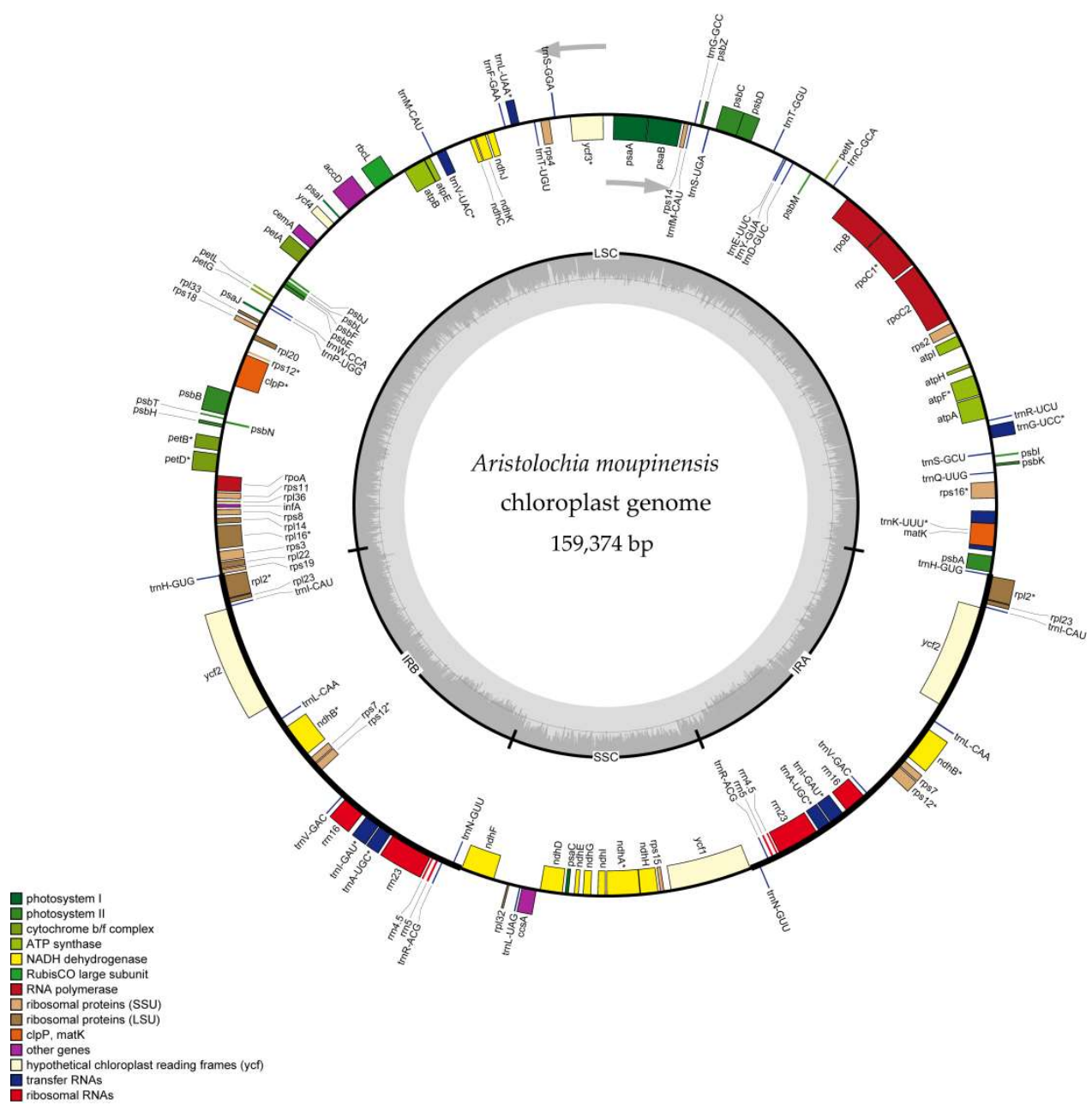

Figure 1. Cont. 
B

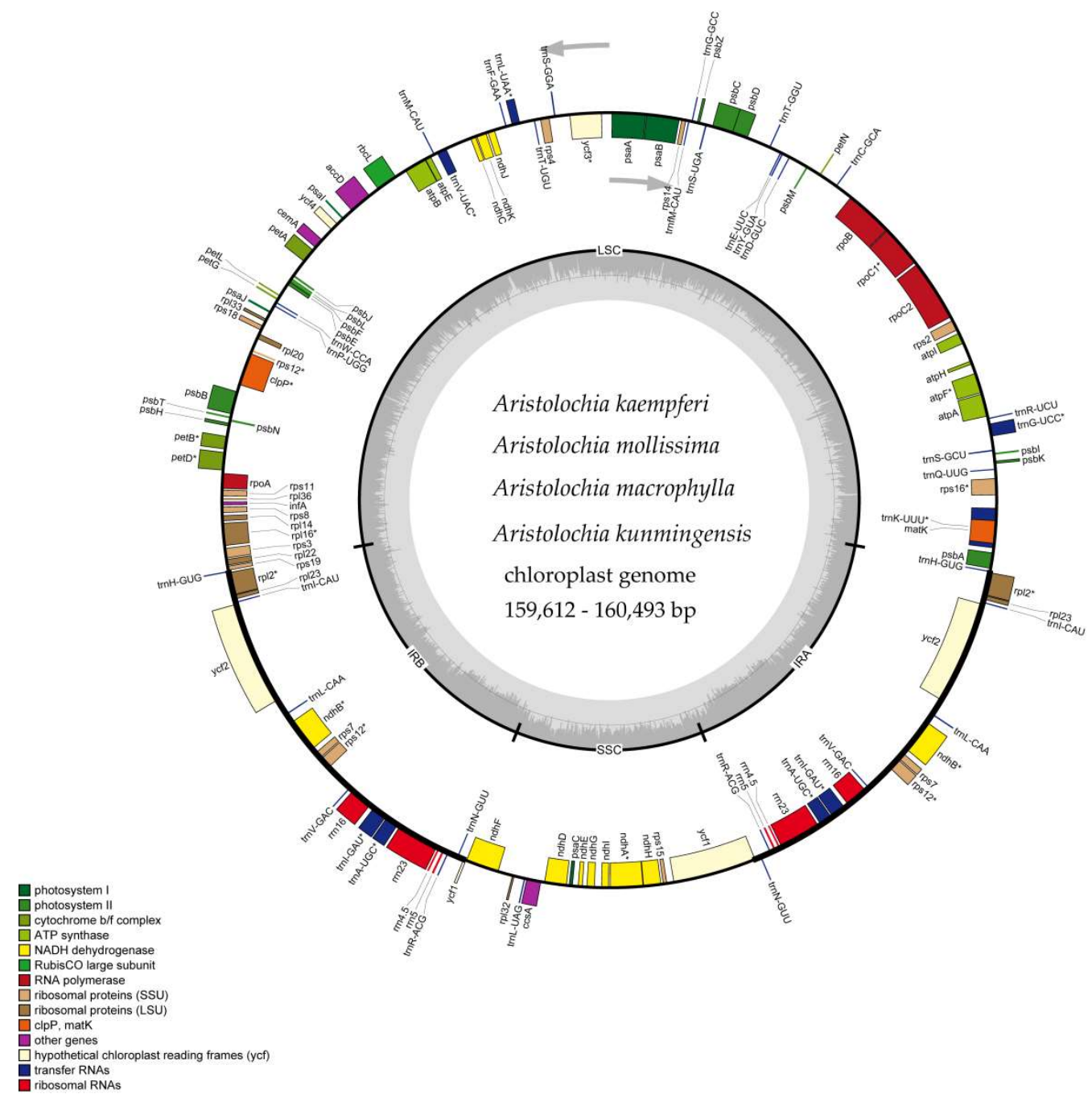

Figure 1. Cont. 
C

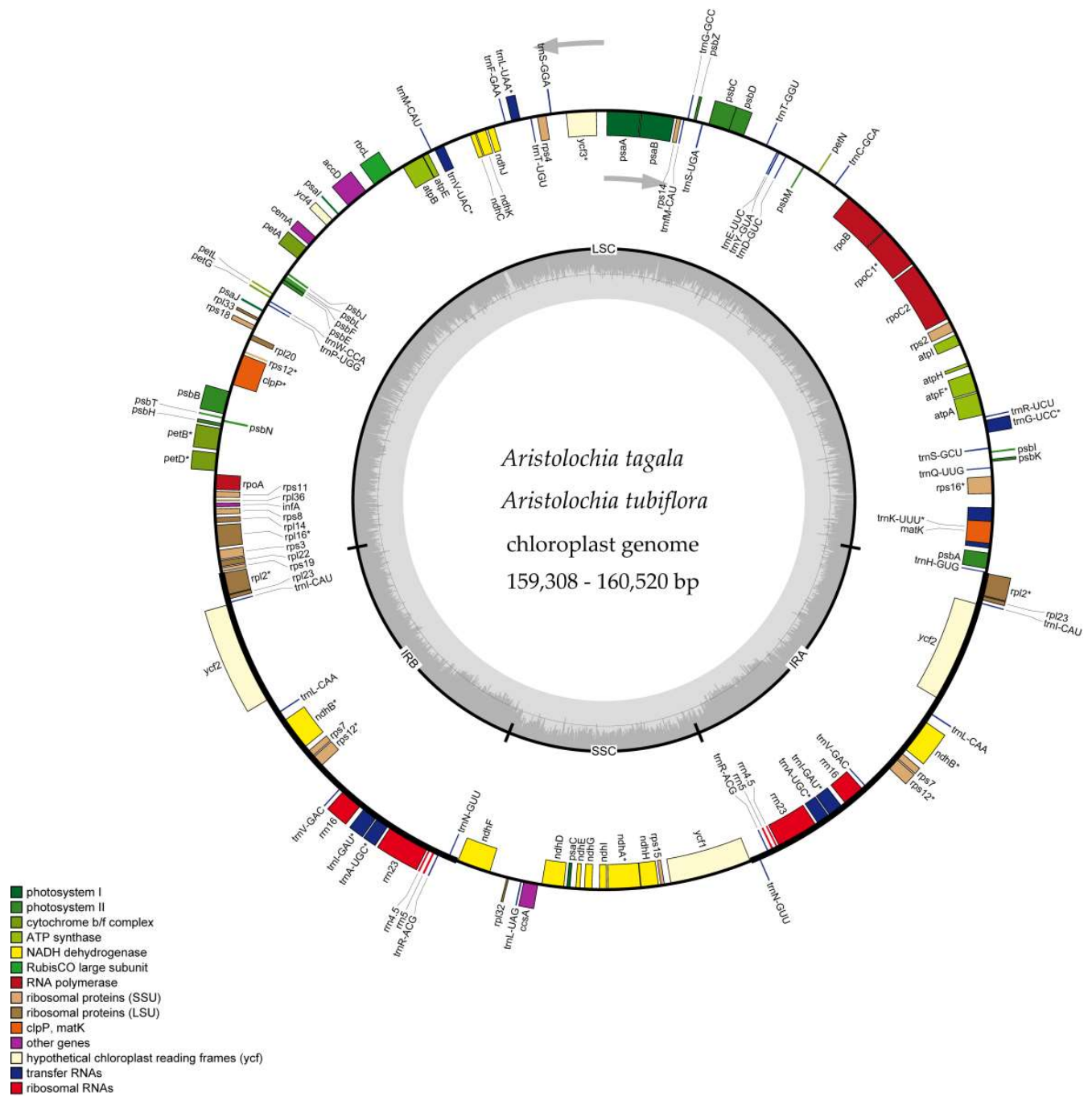

Figure 1. Gene maps of the complete $\mathrm{cp}$ genome of seven species of Aristolochia. Gene map of $\mathrm{cp}$ genome of (A) Aristolochia manshuriensis; (B) Aristolochia kaempferi, Aristolochia macrophylla, Aristolochia mollissima and Aristolochia kunmingensis; (C) Aristolochia tagala and Aristolochia tubiflora. Genes on the inside of the circle are transcribed clockwise, while those outside are transcribed counter clockwise. The darker gray in the inner circle corresponds to GC content, whereas the lighter gray corresponds to AT content.

Table 1. Summary of complete chloroplast (cp) genomes of Aristolochia species.

\begin{tabular}{ccccccccccc}
\hline Species & Total & LSC & IR & SSC & CDS & Total & $\begin{array}{c}\text { Protein Coding } \\
\text { Genes }\end{array}$ & tRNA & rRNA & GC\% \\
\hline $\begin{array}{c}\text { A. kaempferi } \\
\text { A. }\end{array}$ & 159,612 & 88,890 & 25,681 & 19,360 & 79191.0 & 113 & 79 & 30 & 4 & 38.8 \\
$\begin{array}{c}\text { kunmingensis } \\
\quad \text { A. }\end{array}$ & 160,051 & 89,308 & 25,698 & 19,347 & 79143.0 & 113 & 79 & 30 & 4 & 38.7 \\
$\begin{array}{c}\text { macrophylla } \\
\text { A. mollissima }\end{array}$ & 160,493 & 89,788 & 25,664 & 19,377 & 79116.0 & 113 & 79 & 30 & 4 & 38.6 \\
$\begin{array}{c}\text { A. } \\
\text { moupinensis }\end{array}$ & 159,374 & 88,948 & 25,681 & 19,338 & 79194.0 & 113 & 79 & 30 & 4 & 38.8 \\
A. tagala & 159,308 & 89,414 & 25,242 & 19,410 & 78582.0 & 113 & 79 & 30 & 4 & 38.5 \\
A. tubiflora & 160,520 & 89,859 & 25,431 & 19,799 & 78624.0 & 113 & 79 & 30 & 4 & 38.8 \\
\hline
\end{tabular}


Table 2. Gene contents in the cp genomes of Aristolochia species.

\begin{tabular}{|c|c|c|c|}
\hline No. & Group of Genes & Genes Names & Amount \\
\hline 1 & Photosystems I & $p s a A, p s a B, p s a C, p s a I, p s a J$ & 5 \\
\hline 2 & Photosystems II & $\begin{array}{l}p s b A, p s b B, p s b C, p s b E, p s b F, p s b H, p s b I, \\
p s b J, p s b K, p s b L, p s b M, p s b N, p s b T, p s b Z\end{array}$ & 15 \\
\hline 3 & Cytochrome b/f complex & $\operatorname{pet} A, \operatorname{pet} B^{*}, \operatorname{pet} D^{*}, \operatorname{pet} G, \operatorname{pet} L, \operatorname{pet} N$ & 6 \\
\hline 4 & ATP synthase & $\operatorname{atp} A, \operatorname{atp} B, \operatorname{atp} E, \operatorname{atpF} F^{*}, \operatorname{atpH}$, atpI & 6 \\
\hline 5 & NADH dehydrogenase & $\begin{array}{c}n d h A *, n d h B *(x 2), n d h C, n d h D, n d h E, \\
n d h F, n d h G, n d h H, n d h I, n d h J, n d h K\end{array}$ & $12(1)$ \\
\hline 6 & Rubisco large subunit & $r b c L$ & 1 \\
\hline 7 & RNA polymerase & $r p o A, r p o B, r p o C 1 *$, rpoC2 & 4 \\
\hline 8 & Ribosomal proteins(SSU) & $\begin{array}{l}r p s 2, r p s 3, r p s 7(x 2), r p s 8, r p s 11, r p s 12 \\
* *(x 2), r p s 14, r p s 15, r p s 16 *, r p s 18, r p s 19\end{array}$ & $14(2)$ \\
\hline 9 & Ribosomal proteins(LSU) & $\begin{array}{c}r p l 2{ }^{*}(x 2), \text { rpl14, rpl16* }{ }^{*} \text {, rpl20, rpl22, } \\
\text { rpl23(x2), rpl32, rpl33, rpl36 }\end{array}$ & $11(2)$ \\
\hline 10 & $\begin{array}{l}\text { Assembly/stability of } \\
\text { photosystem I }\end{array}$ & $y c f 3^{* *}, y c f 4$ & 2 \\
\hline 11 & Transfer RNAs & $\begin{array}{c}37 / 38 \text { tRNAs (6 contain an intron, } 7 / 8 \text { in the } \\
\text { IRs) }\end{array}$ & $37(7) / 38(8)$ \\
\hline 12 & Ribosomal RNAs & $r r n 4.5(x 2), r r n 5(x 2), r r n 16(x 2), r r n 23(x 2)$ & $8(8)$ \\
\hline 13 & RNA processing & matK & 1 \\
\hline 14 & Carbon metabolism & $\operatorname{cem} A$ & 1 \\
\hline 15 & Cytochrome c synthesis & $\operatorname{ccs} A$ & 1 \\
\hline 16 & $\begin{array}{l}\text { Proteins of unknown } \\
\text { function }\end{array}$ & $y c f 1, y c f 2(x 2)$ & $3(1)$ \\
\hline 17 & Other genes & $a c c D, \operatorname{clp} P^{* *}, \inf A$ & 3 \\
\hline
\end{tabular}

${ }^{*}$ Gene contains one intron; ${ }^{* *}$ gene contains two introns; (x2) indicates the number of the repeat unit is 2.

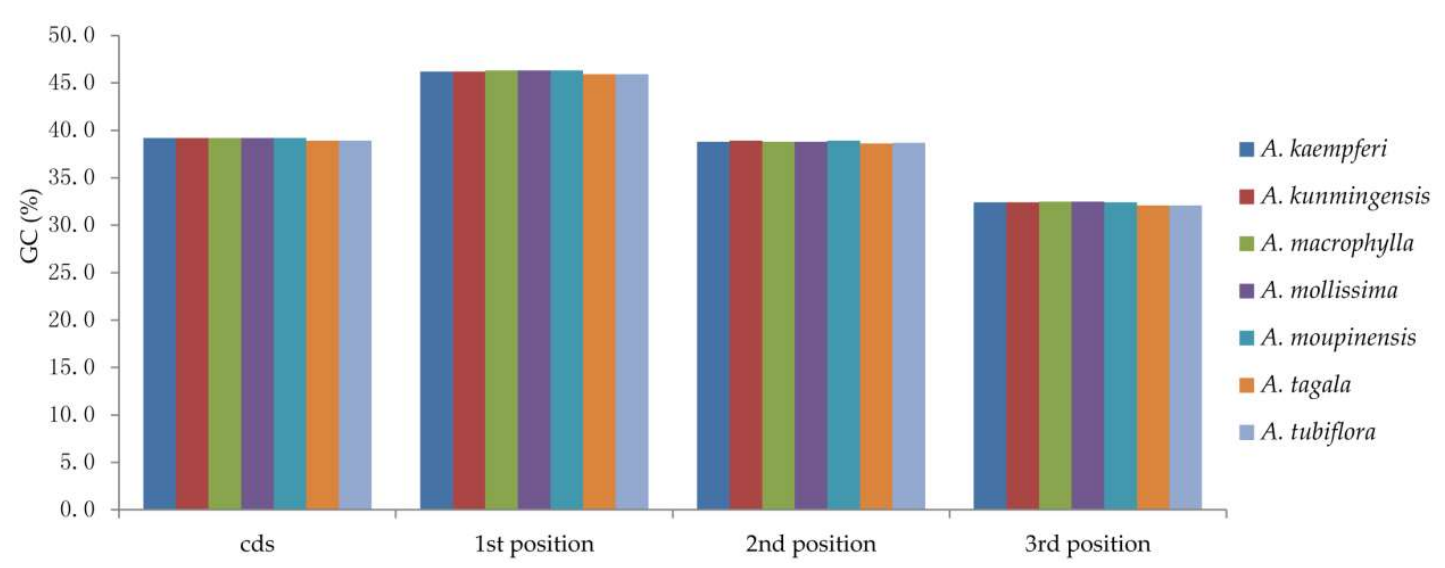

Figure 2. The GC (\%) composition in different positions of coding sequence (CDS) region of species within Aristolochia.

Introns play an important role in the regulation of some gene expressions [33]. Eighteen genes of seven plastomes contain one intron, including $a t p F, r p o C 1, y c f 3, r p s 12, r p l 2, r p l 16, \operatorname{clpP}, \operatorname{pet} B, p e t D$, $r p s 16, n d h A, n d h B$, and six tRNA genes, while three genes ( $c l p P, y c f 3$, and $r p s 12)$ contain two introns. The longest intron occurred in the trnK-UUU gene is $2552-2687 \mathrm{bp}$ of seven plastomes, and had been used to the inter- and intra-species of Aristolochia [2,16]. In addition, the length of rpl2 intron in species of subgenus Siphisia and subgenus Aristolochia is $700 \mathrm{bp}$ and $659 \mathrm{bp}$, respectively (Table 3). 
Table 3. Genes with introns in the seven cp genomes of Aristolochia as well as the lengths of the exons and introns.

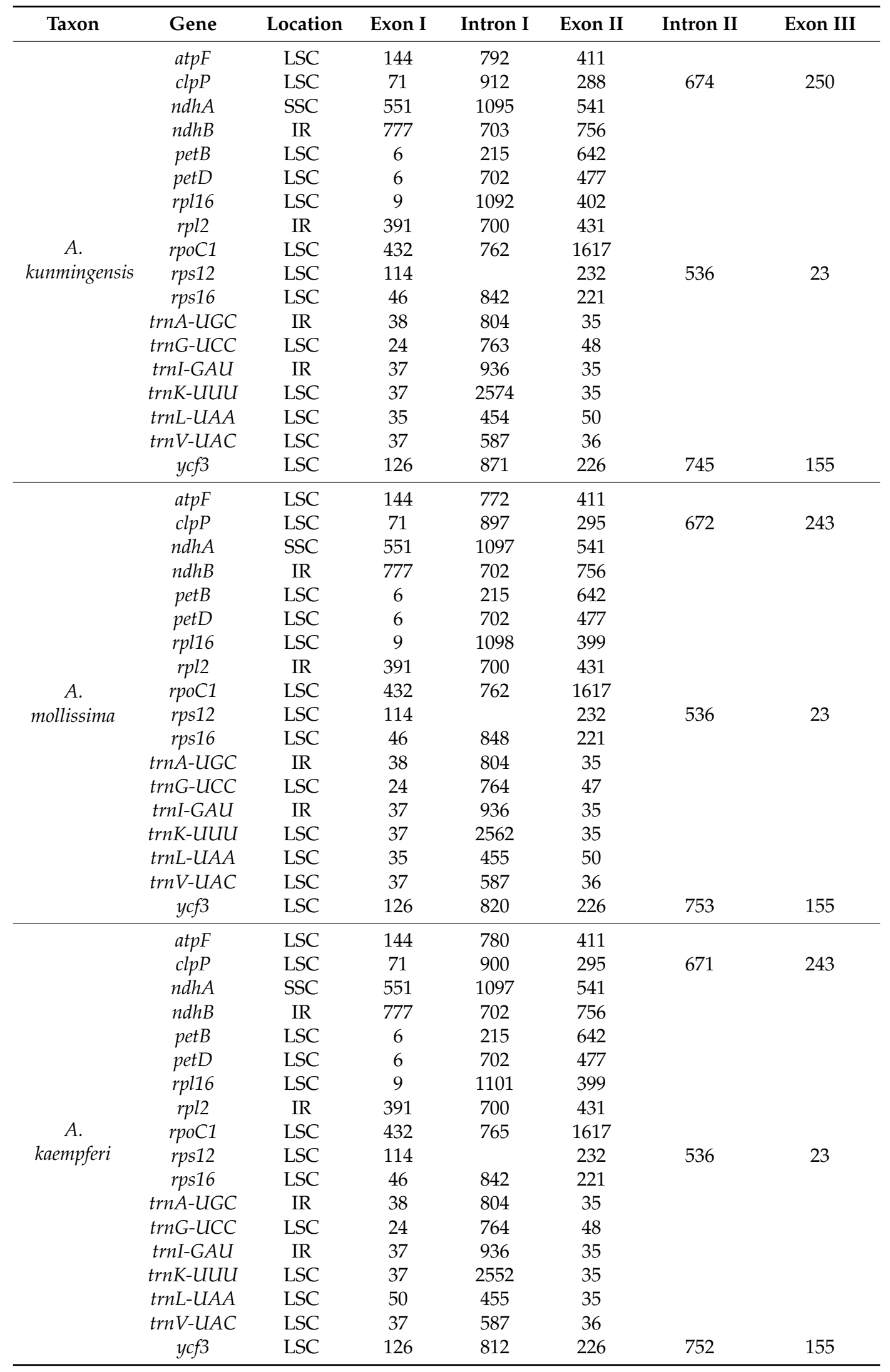


Table 3. Cont.

\begin{tabular}{|c|c|c|c|c|c|c|c|}
\hline Taxon & Gene & Location & Exon I & Intron I & Exon II & Intron II & Exon III \\
\hline \multirow{18}{*}{$\begin{array}{c}\text { A. } \\
\text { moupinensis }\end{array}$} & $\operatorname{atpF}$ & LSC & 144 & 789 & 411 & \multirow{3}{*}{669} & \multirow{3}{*}{250} \\
\hline & $c l p P$ & LSC & 71 & 909 & 288 & & \\
\hline & $n d h A$ & SSC & 551 & 1101 & 541 & & \\
\hline & $n d h B$ & IR & 777 & 703 & 756 & \multirow{14}{*}{536} & \multirow{14}{*}{23} \\
\hline & $\operatorname{pet} B$ & LSC & 6 & 211 & 646 & & \\
\hline & petD & LSC & 6 & 708 & 477 & & \\
\hline & rpl16 & LSC & 399 & 1100 & 9 & & \\
\hline & $r p l 2$ & IR & 391 & 700 & 431 & & \\
\hline & rpoC1 & LSC & 432 & 764 & 1617 & & \\
\hline & rps12 & LSC & 114 & & 232 & & \\
\hline & rps16 & LSC & 46 & 839 & 221 & & \\
\hline & $\operatorname{trn} A-U G C$ & IR & 38 & 804 & 35 & & \\
\hline & $\operatorname{trn} G-U C C$ & LSC & 24 & 758 & 48 & & \\
\hline & trnI-GAU & IR & 37 & 936 & 35 & & \\
\hline & trnK-UUU & LSC & 37 & 2567 & 35 & & \\
\hline & $\operatorname{trnL}-U A A$ & LSC & 35 & 462 & 50 & & \\
\hline & $\operatorname{trn} V-U A C$ & LSC & 37 & 587 & 36 & & \\
\hline & $y c f 3$ & LSC & 126 & 920 & 226 & 746 & 155 \\
\hline \multirow{18}{*}{$\begin{array}{c}A . \\
\text { macrophylla }\end{array}$} & atpF & LSC & 144 & 778 & 411 & \multirow{9}{*}{664} & \multirow{9}{*}{250} \\
\hline & $c l p P$ & LSC & 71 & 928 & 288 & & \\
\hline & $n d h A$ & SSC & 551 & 1084 & 541 & & \\
\hline & $n d h B$ & IR & 777 & 702 & 756 & & \\
\hline & petB & LSC & 6 & 215 & 642 & & \\
\hline & petD & LSC & 6 & 706 & 477 & & \\
\hline & rpl16 & LSC & 9 & 1095 & 402 & & \\
\hline & $r p l 2$ & IR & 391 & 700 & 431 & & \\
\hline & rpoc1 & LSC & 432 & 788 & 1617 & & \\
\hline & rps12 & LSC & 114 & & 232 & \multirow[t]{8}{*}{536} & \multirow[t]{8}{*}{23} \\
\hline & rps16 & LSC & 46 & 836 & 221 & & \\
\hline & $\operatorname{trn} A-U G C$ & IR & 38 & 804 & 35 & & \\
\hline & $\operatorname{trn} G-U C C$ & LSC & 24 & 755 & 47 & & \\
\hline & trnI-GAU & IR & 37 & 936 & 35 & & \\
\hline & trnK-UUU & LSC & 37 & 2558 & 35 & & \\
\hline & trnL-UAA & LSC & 35 & 475 & 50 & & \\
\hline & $\operatorname{trn} V-U A C$ & LSC & 37 & 589 & 36 & & \\
\hline & $y c f 3$ & LSC & 126 & 892 & 226 & 757 & 155 \\
\hline \multirow{18}{*}{ A.tubiflora } & $\operatorname{atpF}$ & LSC & 144 & 751 & 411 & \multirow{9}{*}{671} & \multirow{9}{*}{250} \\
\hline & $c l p P$ & LSC & 71 & 819 & 288 & & \\
\hline & $n d h A$ & SSC & 551 & 1079 & 541 & & \\
\hline & $n d h B$ & IR & 777 & 705 & 756 & & \\
\hline & petB & LSC & 6 & 214 & 642 & & \\
\hline & petD & LSC & 6 & 693 & 477 & & \\
\hline & rpl16 & LSC & 9 & 1077 & 399 & & \\
\hline & $r p l 2$ & IR & 391 & 657 & 431 & & \\
\hline & rpoC1 & LSC & 432 & 780 & 1617 & & \\
\hline & rps12 & LSC & 114 & & 232 & \multirow[t]{8}{*}{536} & \multirow[t]{8}{*}{23} \\
\hline & rps16 & LSC & 46 & 889 & 221 & & \\
\hline & $\operatorname{trn} A-U G C$ & IR & 38 & 809 & 35 & & \\
\hline & $\operatorname{trn} G-U C C$ & LSC & 24 & 768 & 47 & & \\
\hline & trnI-GAU & IR & 37 & 937 & 35 & & \\
\hline & trnK-UUU & LSC & 37 & 2635 & 35 & & \\
\hline & $\operatorname{trnL-UAA}$ & LSC & 35 & 514 & 50 & & \\
\hline & $\operatorname{trn} V-U A C$ & LSC & 37 & 594 & 36 & & \\
\hline & $y c f 3$ & LSC & 126 & 764 & 226 & 752 & 149 \\
\hline
\end{tabular}


Table 3. Cont.

\begin{tabular}{|c|c|c|c|c|c|c|c|}
\hline Taxon & Gene & Location & Exon I & Intron I & Exon II & Intron II & Exon III \\
\hline \multirow{18}{*}{ A. tagala } & $\operatorname{atpF}$ & LSC & 144 & 778 & 408 & \multirow{3}{*}{671} & \multirow{3}{*}{250} \\
\hline & $\operatorname{clpP}$ & LSC & 71 & 802 & 288 & & \\
\hline & $n d h A$ & SSC & 551 & 1101 & 541 & & \\
\hline & $n d h B$ & IR & 777 & 704 & 756 & \multirow{14}{*}{536} & \multirow{14}{*}{23} \\
\hline & petB & LSC & 6 & 219 & 642 & & \\
\hline & petD & LSC & 6 & 488 & 477 & & \\
\hline & rpl16 & LSC & 9 & 1071 & 399 & & \\
\hline & $r p l 2$ & IR & 391 & 657 & 431 & & \\
\hline & rpoc1 & LSC & 432 & 785 & 1617 & & \\
\hline & rps12 & LSC & 114 & & 232 & & \\
\hline & rps16 & LSC & 46 & 848 & 221 & & \\
\hline & $\operatorname{trn} A-U G C$ & IR & 38 & 804 & 35 & & \\
\hline & trnG-UCC & LSC & 24 & 768 & 48 & & \\
\hline & $\operatorname{trnI-GAU}$ & IR & 37 & 743 & 35 & & \\
\hline & trnK-UUU & LSC & 37 & 2687 & 35 & & \\
\hline & trnL-UAA & LSC & 35 & 490 & 50 & & \\
\hline & $\operatorname{trn} V-U A C$ & LSC & 37 & 595 & 36 & & \\
\hline & $y c f 3$ & LSC & 126 & 830 & 226 & 763 & 149 \\
\hline
\end{tabular}

\subsection{IR Contraction and Expansion}

The IR regions are expanded in five species of subgenus Siphisia compare with other two species (A. tagala and A. tubiflora) of subgenus Aristolochia, indicated by different duplication genes in the IR regions, where eight or seven tRNA genes were duplicated, respectively (Figure 1, Table 2). The size of the IR region of subgenus Siphisia varies from 25,664 bp to 25,700 bp, and is 25,242 bp and 25,431 bp in the two plastomes of subgenus Aristolochia (Table 1).

Fluctuation of IR-SC borders, together with the adjacent genes, were examined among seven Aristolochia species and six plastomes retrieved from GenBank (including Aristolochia contorta: NC_036152.1, Aristolochia debilis: NC_036153.1, Asarum canadense: MG544845-MG544851, Saruma henryi: MG520100, Piper auritum: NC_034697.1, and Drimys granadensis: NC_008456.1) (Figure 3). The LSC-IRb border, was located within the genic spacer of rps19-trnH for A. kaempferi, A. macrophylla, and A. mollissima (Type I), within the rps19 gene for A. kunmingensis and A. moupinensis (Type II), while in the rps19-rpl2 spacer for $A$. tagala and A. tubiflora (Type III). There were two types of SSC-IRa border among 13 detected species. In the three plastomes (A. moupinensis, A. tubiflora, and A. tagala), which ycf1 gene was fully located in the SSC region, and 25-43 bp apart from the SSC-IRa border. The SSC-IRa border was situated in the coding region $y c f 1$ gene in the other 10 sequenced species, which spanned into the IRa region. Among the 10 detected species, the pseudogene ycf1 in the IRb region with the same length as far as the IRa expanded into ycf1 gene, and the length ranged from $153 \mathrm{bp}$ to $2271 \mathrm{bp}$. The $n d h F$ gene was entirely located in the SSC region in 10 species of Aristolochiaceae, but varied in distance (11-80 bp) from the IRb-SSC border. The LSC-IRa border in the species of subgenus Aristolochia was situated in the $t r n H$ gene with $10 \mathrm{bp}$ into the IRa region (Type III), while the border was located in the trnH-psbA spacer in subgenus Siphisia species (Type I and II) (Figure 3). 


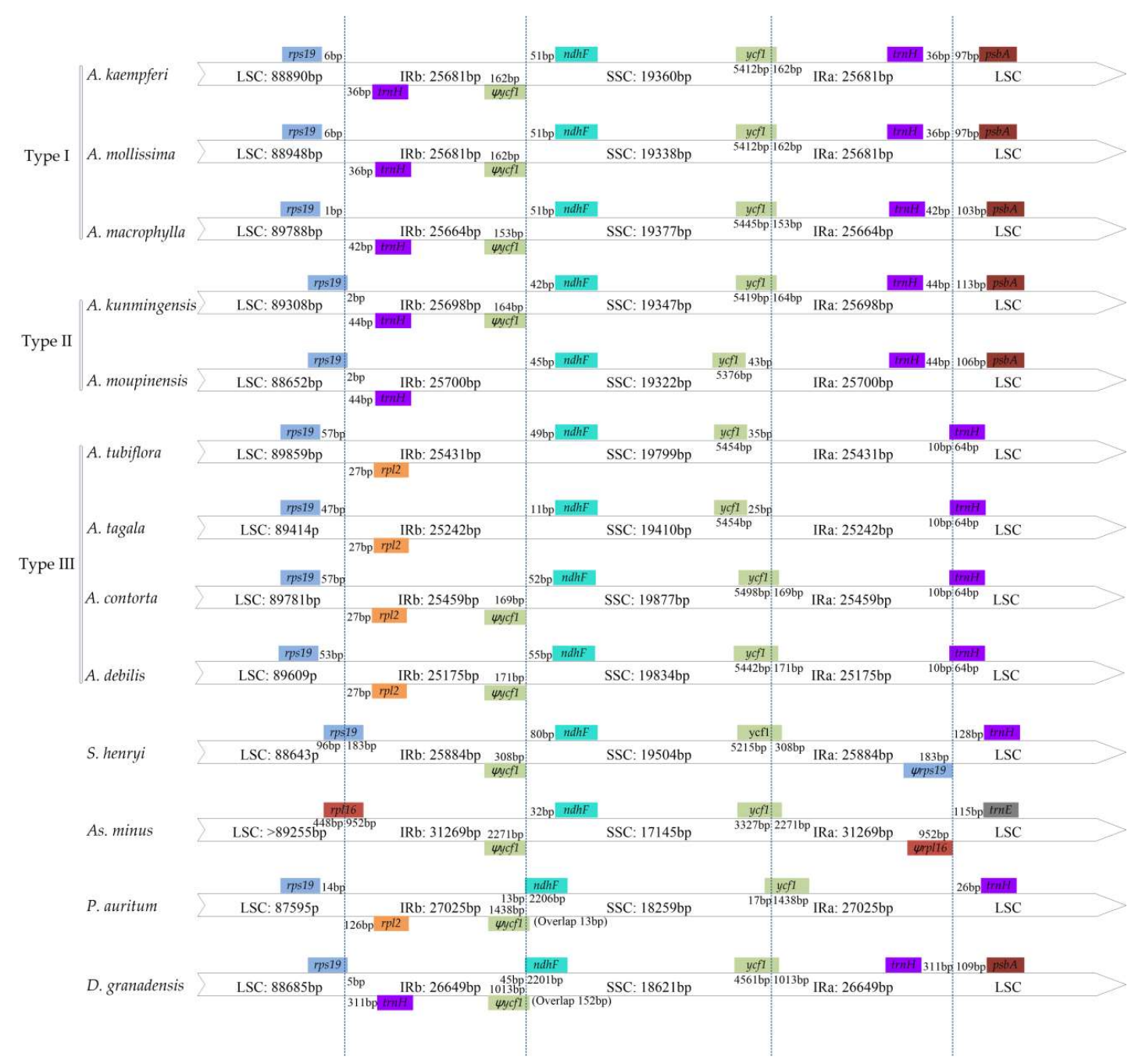

Figure 3. Comparison of the borders of large single copy (LSC), small single copy (SSC) and inverted repeat (IR) regions among $13 \mathrm{cp}$ genomes. Number above the gene features means the distance between the ends of genes and the borders sites. These features are not to scale.

\subsection{Codon Usage}

All the protein-coding genes were composed of 26,194-26,398 codons in the cp genomes of the seven species of Aristolochia. The codon usages of protein-coding genes in the cp genomes are summarized in Figure 4 and Table S2. Among these codons, the most common amino acid in the protein-coding genes is leucine, which appears 2775 times in A. kaempferi and A. mollissima. The relative synonymous codon usage (RSCU) value analysis showed that almost all amino acids have more than one synonymous codon, except methionine and tryptophan. Nearly all of the protein-coding genes of Aristolochia species had the standard ATG start codon (RSCU =1). About half of codons have RSCU > 1 , and most of those $(29 / 31,93.5 \%)$ end with base A or T. About half of the codons have RSCU $<1$, and most of those $(28 / 31,90.3 \%)$ end with base C or G. 


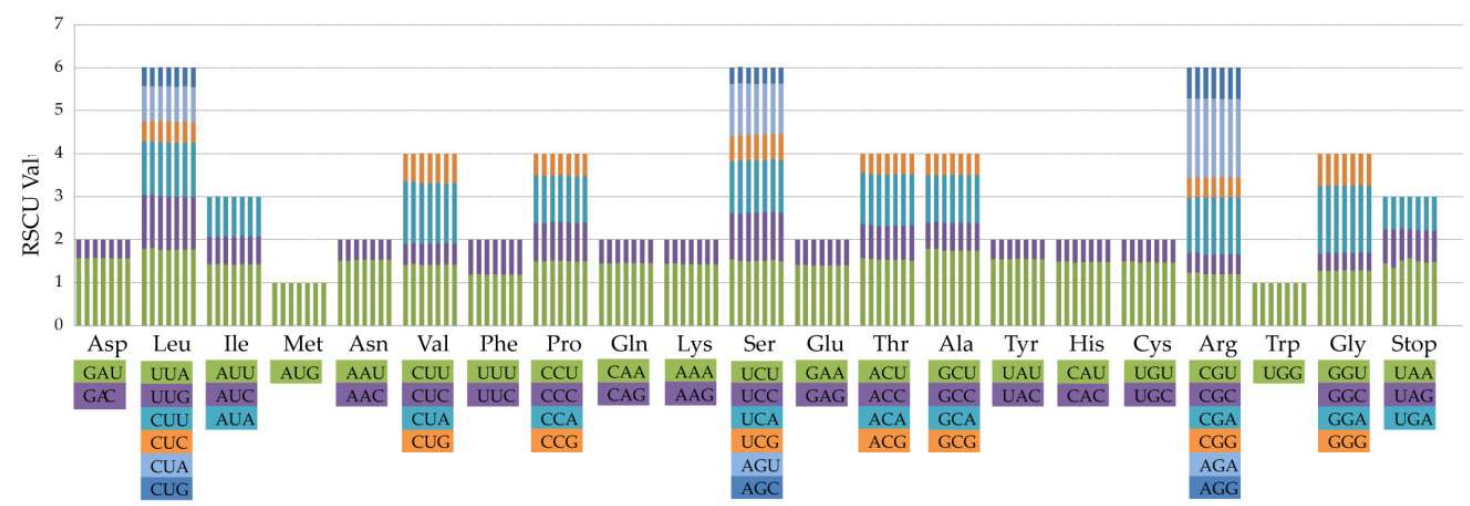

Figure 4. Codon content of 20 amino acid and stop codons in all protein-coding genes of the seven cp genomes. The histogram from the left-hand side of each amino acid shows codon usage within Aristolochia (From left to right: A. tagala, A. tubiflora, A. moupinensis, A. kunmingensis, A. kaempferi, A. macrophylla, and A. mollissima).

\subsection{Positive Selection Analysis}

We compared the ratio of non-synonymous $(\mathrm{dN})$ and synonymous $(\mathrm{dS})$ substitution for 79 protein-coding genes among seven species, including A. kunmingensis, A. kaempferi, A. tagala, A. debilis, As. canadense, S. henryi, and P. auritum within Piperales. The statistical neutrality test showed that five genes in the seven cp genomes are under significant positive selection, and these genes are involved in the synthesis of ribosomal small and large subunit protein (rps12, rps18, and rpl20) or unknown function (ycf1 and ycf2) (Table 4). Likelihood ratio tests (M1a vs. M2a, M7 vs. M8) supported the presence of positively selected codon sites $(p<0.05)$ (Table S3). According to the M2a and M8 models, the $r p l 20$ harbored three or four sites under positive selection. The gene ycf1 harbored one or three sites under positive selection based on two models, respectively. In addition, we identified rps12 gene with one positive selection site.

Table 4. Positive selected sites detected in the cp genome of the Piperales.

\begin{tabular}{ccccc}
\hline \multirow{2}{*}{ Gene Name M2a } & \multicolumn{3}{c}{ M8 } \\
\cline { 2 - 5 } & Selected Sites & $\operatorname{Pr}(\mathbf{w}>\mathbf{1})$ & Selected Sites & $\operatorname{Pr}(\mathbf{w}>\mathbf{1})$ \\
\hline rpl20 & $71 \mathrm{~A}$ & 0.918 & $71 \mathrm{~A}$ & $0.967^{*}$ \\
& $72 \mathrm{~L}$ & $0.999^{* *}$ & $72 \mathrm{~L}$ & $1.000^{* *}$ \\
& $105 \mathrm{R}$ & $0.963^{*}$ & $105 \mathrm{R}$ & $0.984^{*}$ \\
\multirow{2}{*}{$r p s 12$} & $116 \mathrm{H}$ & $0.963^{*}$ & $116 \mathrm{H}$ & $0.988^{*}$ \\
$r p s 18$ & $79 \mathrm{M}$ & $0.966^{*}$ & $79 \mathrm{M}$ & $0.987^{*}$ \\
& $4 \mathrm{~S}$ & 0.937 & $4 \mathrm{~S}$ & $0.975^{*}$ \\
$y c f 1$ & $99 \mathrm{~T}$ & 0.921 & $99 \mathrm{~T}$ & $0.967^{*}$ \\
& $206 \mathrm{~S}$ & 0.914 & $206 \mathrm{~S}$ & $0.967^{*}$ \\
& $211 \mathrm{~V}$ & $0.975^{*}$ & $211 \mathrm{~V}$ & $0.989^{*}$ \\
$y c f 2$ & $1412 \mathrm{~N}$ & 0.922 & $1412 \mathrm{~N}$ & $0.971^{*}$ \\
& $2036 \mathrm{~W}$ & 0.932 & $2036 \mathrm{~W}$ & $0.950^{*}$ \\
\hline
\end{tabular}

\subsection{Repeat Structure and Simple Sequence Repeats Analyses}

Repeats in ten cp genomes were analyzed using REPuter, including seven species of Aristolochia, S. henryi, P. auritum, and D. granadensis (Figure 5, Table S4). The results showed that A. macrophylla had the greatest number of repetitive elements in cp genome, comprised of 25 forward, 26 palindromic, 21 reverse, and eight complement repeats. The size of the most repeats were $30-39 \mathrm{bp}$, and the repeats with the length $>49$ bp only occurred in cp genomes of $S$. henryi and P. auritum. The longest repeats, 
with a length of $1591 \mathrm{bp}$, was detected in S. henryi. The total numbers of SSRs were also identified in the cp genomes of the ten species (Figure 6 and Table S5). Mononucleotide repeats were the largest in a number of these SSRs, with $88 \%$ and $85 \%$ found in A. tubiflora and A. tagala, respectively. A/T repeats were the most common of mononucleotides, while AT/TA repeats are the majority of dinucleotide repeat sequences $(96.3 \%-100 \%)$. The trinucleotide in the five species of subgenus Siphisia were only comprised of AAT/ATT repeats (100\%), while A. tubiflora and A. tagala of subgenus Aristolochia also comprised AAC/GTT and AAG/CTT repeats.

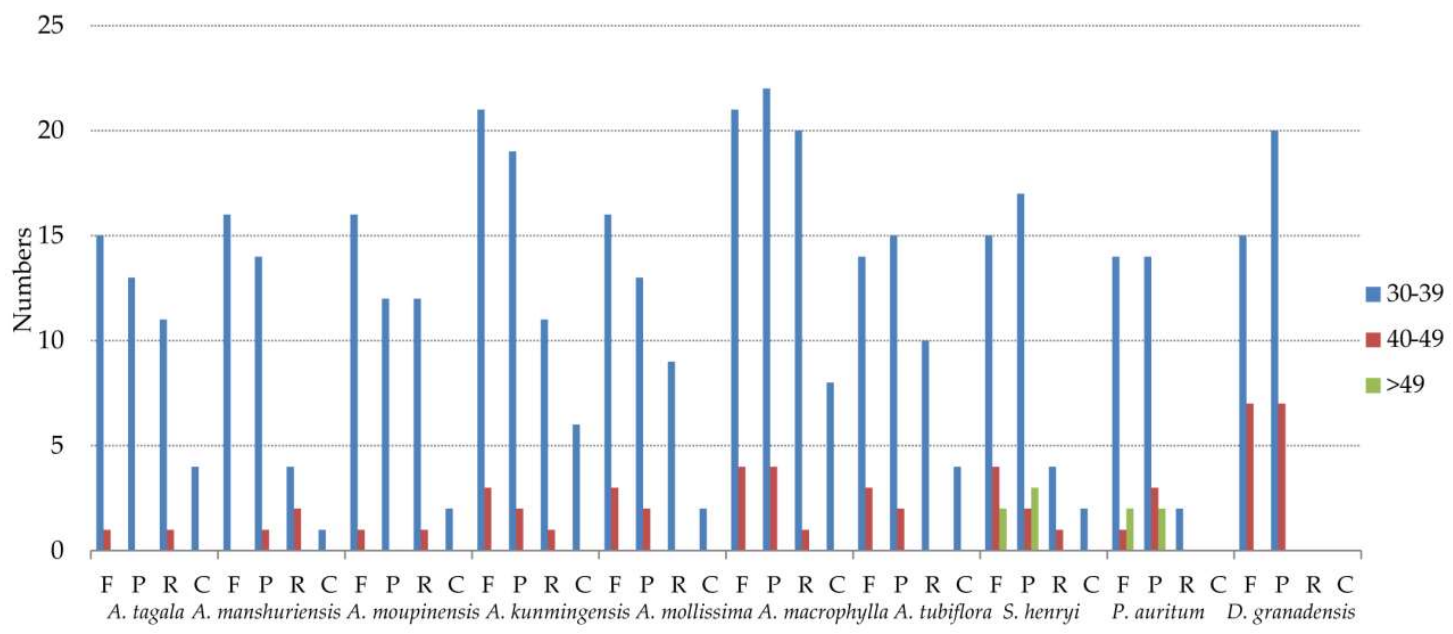

Figure 5. Repeat sequences in ten $c p$ genomes. REPuter was used to identify repeat sequences with length $\geq 30$ bp and sequence identity $\geq 90 \%$ in the cp genomes. F, P, R, and C indicate the repeat types F (forward), P (palindrome), R (reverse), and C (complement), respectively. Repeats with different lengths are indicated in different colors.

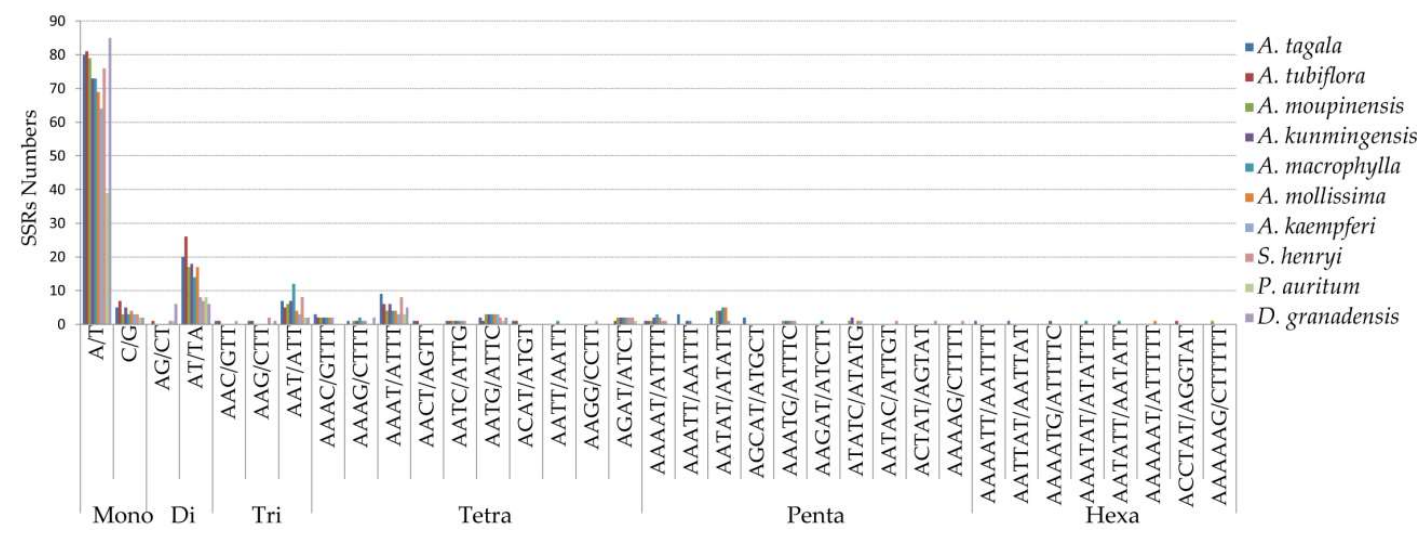

Figure 6. Frequency of simple sequence repeats (SSRs) in the ten cp genomes.

\subsection{Comparative Genomic Divergence and Hotspots Regions}

The SC and IR regions of $\mathrm{cp}$ genomes of the seven species (including A. moupinensis, A. kunmingensis, A. tagala, A. contorta, S. henryi, As. canadense, and P. auritum) were compared using the mVISTA program to detect hyper-variable regions (Figure 7). The alignment revealed high sequence conservatism across the $\mathrm{cp}$ genomes of A. moupinensis and A. kunmingensis of subgenus Siphisia. The comparison among seven cp genomes showed that the IR region was more conserved than the SC regions. The most divergent regions located in the intergenic spacers, and the most divergent coding regions were $n d h F$ and $y c f 1$. 


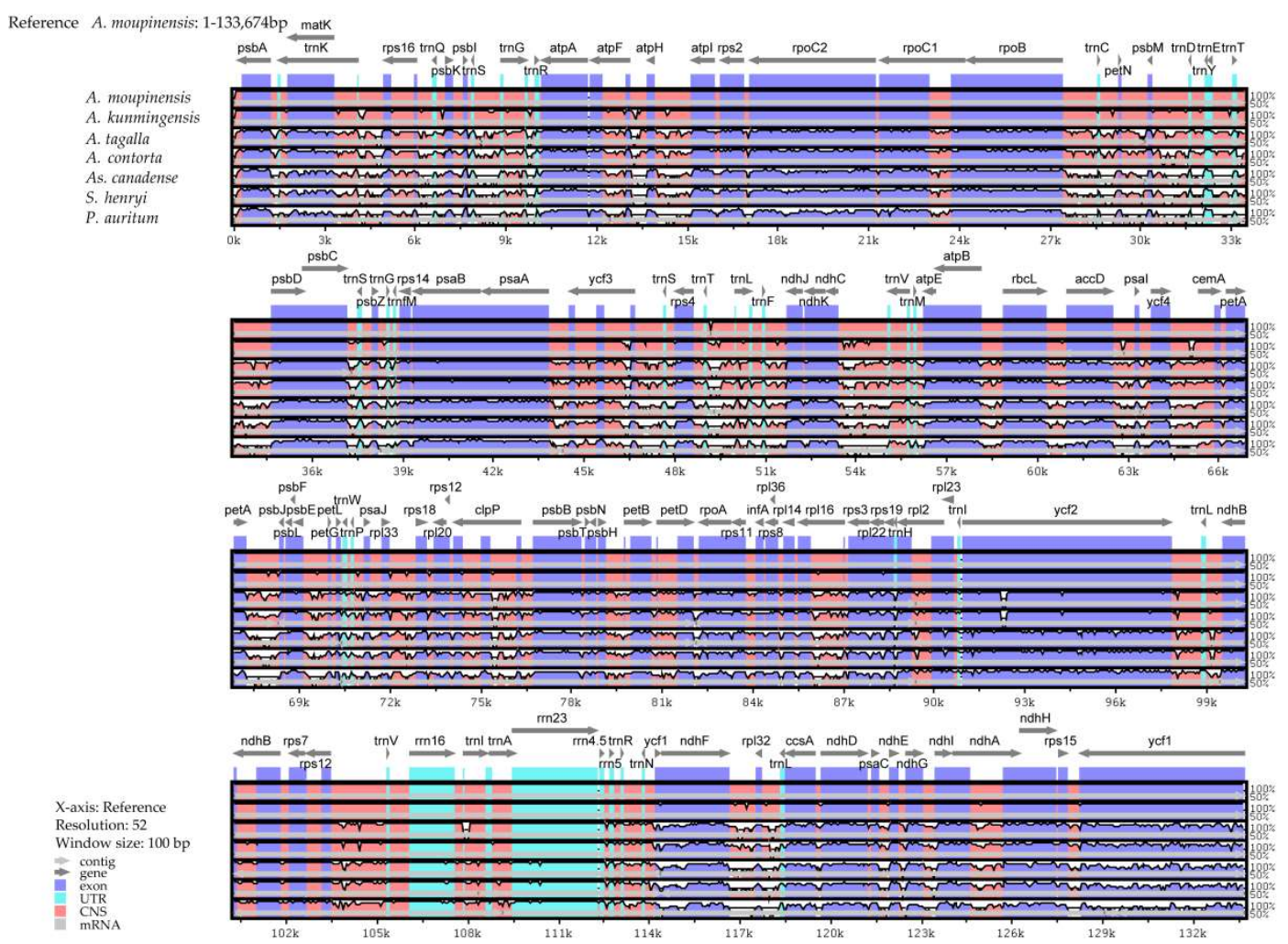

Figure 7. Sequence identity plot compared seven $\mathrm{cp}$ genomes with A. moupinensis as a reference by using mVISTA. Grey arrows and thick black lines above the alignment indicate genes with their orientation and the position of the IRs, respectively. A cut-off of $70 \%$ identity was used for the plots, and the $Y$-scale represents the percent identity from $50 \%$ to $100 \%$.

Comparative analysis among our seven sequenced species within Aristolochia was conducted of the entire cp genomes, LSC, SSC, IR, and CDS regions, respectively (Table 5). The nucleotide diversity (Pi) value was also calculated to evaluate the sequence divergence among these cp genomes, and their values varied from 0 to 0.07746 (Figure 8). The analysis revealed that the SSC region, compared with other regions, exhibited the highest levels of divergence $(\mathrm{Pi}=0.03114)$. These values of the LSC region, varied from 0.00175 to 0.07746 , with the mean value of 0.02182 . The IR region exhibited the lowest Pi values varying from 0 to 0.01056 , with the mean of 0.00411 , indicating that IR region was the most conserved one. Furthermore, we identified 16 hotspot regions $(\mathrm{Pi}>0.04$, the mean value $=0.05413$ ) with the full length of 20,296 bp, including rps16-trnQ-psbK, psbI-trnS-trnG, atpH-atpI, psbM-trnD, rps4-trnT-trnL, trnF-ndhJ, ndhC-trnV, accD-psaI, petA-psbJ, rps18-rpl20, trnN-ndhF, rpl32-trnL-ccsA, and four regions of ycf1 coding gene (Table 6). Ten of these (rps16-trnQ-psbK, psbI-trnS-trnG, atpH-atpI, psbM-trnD, rps4-trnT-trnL, trnF-ndhJ, ndhC-trnV, accD-psaI, petA-psbJ, and rps18-rpl20) are located in the LSC, and six (trnN-ndhF, rpl32-trnL-ccsA and ycf1) in the SSC region, which could be utilized as potential markers for the phylogeny reconstruction and species identification of this subgenus in further studies.

Table 5. Variable sites analyses in the seven Aristolochia cp genomes.

\begin{tabular}{ccccc}
\hline Regions & Number of Sites & Variable Sites & $\begin{array}{c}\text { Parsimony } \\
\text { Informative Sites }\end{array}$ & $\begin{array}{c}\text { Nucleotide } \\
\text { Diversity }\end{array}$ \\
\hline LSC & 94,564 & 4430 & 2315 & 0.02182 \\
SSC & 20,451 & 1433 & 804 & 0.03114 \\
IR & 25,884 & 253 & 154 & 0.00411 \\
Complete & 166,113 & 6422 & 3461 & 0.01717 \\
CDS & 79,365 & 2528 & 1376 & 0.01337 \\
\hline
\end{tabular}




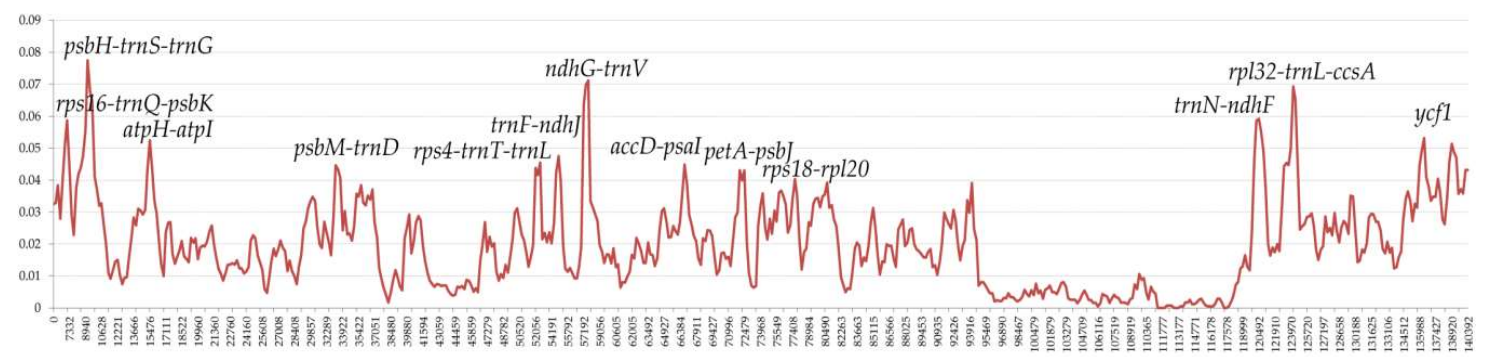

Figure 8. Sliding window analysis of the entire cp genome of seven Aristolochia species (window length: 600 bp; step size: 200 bp). X-axis: position of the midpoint of a window; $Y$-axis: nucleotide diversity of each window.

Table 6. Sixteen regions of highly variable sequences ( $\mathrm{Pi}>0.04)$ of Aristolochia.

\begin{tabular}{ccccc}
\hline $\begin{array}{c}\text { High Variable } \\
\text { Marker }\end{array}$ & Length & Variable Sites & $\begin{array}{c}\text { Parsimony } \\
\text { Informative Sites }\end{array}$ & $\begin{array}{c}\text { Nucleotide } \\
\text { Diversity }\end{array}$ \\
\hline rps16-trnQ-psbK & 1301 & 104 & 58 & 0.04278 \\
psbI-trnS-trnG & 2357 & 257 & 159 & 0.05364 \\
atpH-atpI & 1160 & 104 & 69 & 0.04439 \\
psbM-trnD & 1119 & 152 & 75 & 0.05888 \\
$r p s 4-t r n T-t r n L$ & 1572 & 105 & 50 & 0.04178 \\
trnF-ndhJ & 920 & 85 & 51 & 0.04216 \\
ndhC-trnV & 1402 & 152 & 97 & 0.06311 \\
accD-psaI & 637 & 61 & 35 & 0.04220 \\
petA-psbJ & 1130 & 106 & 65 & 0.04444 \\
$r p s 18-r p l 20$ & 682 & 58 & 36 & 0.04155 \\
trnN-ndhF & 1492 & 161 & 86 & 0.04758 \\
$r p l 32-t r n L-c c s A$ & 2679 & 202 & 113 & 0.04608 \\
$y c f 1 a$ & 1225 & 126 & 74 & 0.04285 \\
$y c f 1 b$ & 652 & 56 & 32 & 0.04053 \\
$y c f 1 c$ & 1228 & 134 & 84 & 0.04611 \\
$y c f 1 d$ & 740 & 70 & 39 & 0.04278 \\
Combine & 20296 & 2216 & 1349 & 0.05413 \\
\hline
\end{tabular}

\subsection{Phylogenetic Analyses}

The phylogenetic relationships of Aristolochiaceae were constructed based on six datasets (entire cp genome sequences except a copy of IR, LSC, SSC, IR, and CDS regions and combining 16 hotspots) of 18 samples, using three methods of ML, MP, and BI, respectively (Figure 9). The robust topologies were consistent for most clades of cp genomes, LSC, SSC, CDS, and hotspots datasets, with the high bootstrap values for most of the branches (Figure 9A). From these six different datasets, the phylogenetic analysis showed that the genera Asarum and Saruma represented by seven species formed a clade with posterior probabilities (PP) $=1$ based on BI, bootstrap values (\%) (BS) $=100$ based on ML and $\mathrm{BS}=100$ based on MP methods. However, the tree constructed using sequences of the IR region failed to resolve the phylogeny position of Asarum epigynum and As. canadense (Figure 9B), maybe due to inadequate information sites in the IR region. These nine species of Aristolochia species formed another strongly supported monophyletic group (PP = 1; [ML] BS = 100; [MP] BS =100), and were divided into two subclades with strong support, corresponding to the taxonomic division of subgenus Siphisia $(\mathrm{PP}=1$; [ML] BS = 100; [MP] BS = 100) and subgenus Aristolochia $(\mathrm{PP}=1$; [ML] BS = 100; [MP] $\mathrm{BS}=100)$. Within the subgenus Siphisia, the species A. macrophylla from North America was sister to the rest of four species from Asian region (PP = 1; [ML] BS = 100; [MP] BS = 100). 


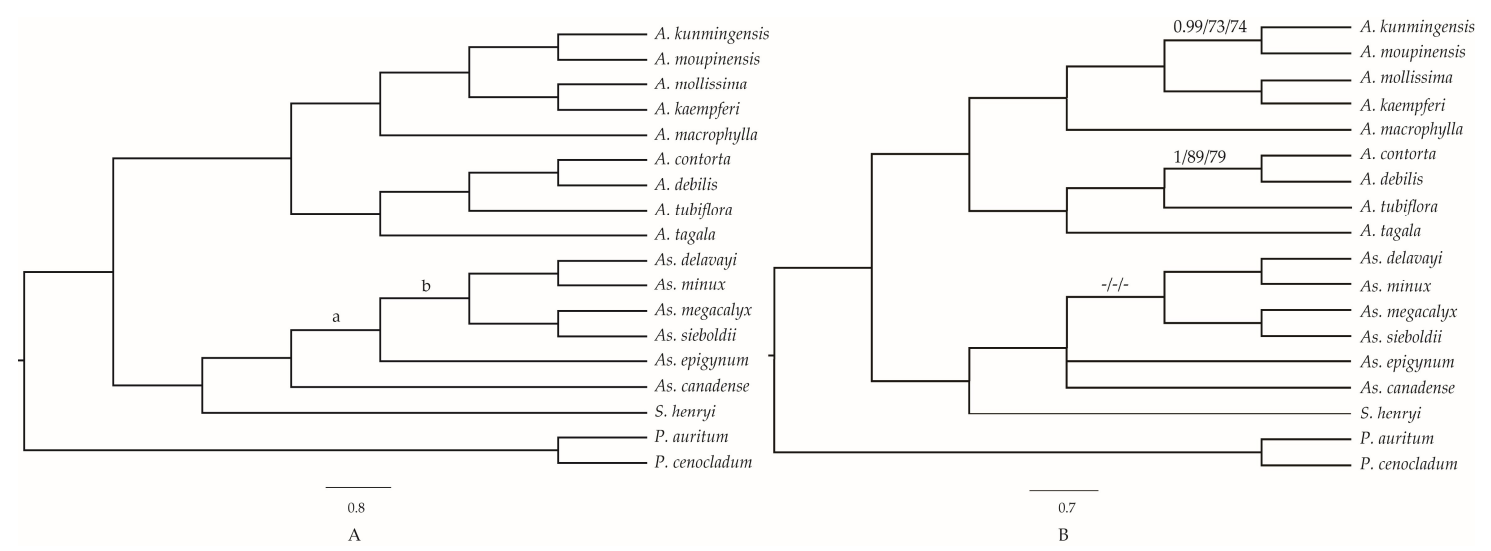

Figure 9. Phylogenetic relationships of the 18 species inferred from maximum parsimony (MP), maximum likelihood (ML), and Bayesian (BI) analyses. (A) The topology was constructed by cp genomes, LSC, SSC, CDS, and hotspots regions; (B) tree constructed by IR region. Bayesian posterior probability values $<0.95$ or Bootstrap values $<90$ were marked on the branches. The support values in node (a): 1/86/93 (using LSC region), 0.97/78/84 (SSC), 0.82/-/- (CDS), and 1/81/80 (hotspots); (b): 1/90/79 (SSC) and 1/73/71 (hotspots). Numbers above nodes are support values with Bayesian posterior probabilities values on the left, ML bootstrap values in the middle, and MP bootstrap values on the right. " - " indicates the value $<70$.

\section{Discussion}

\subsection{IR Contraction and Expansion}

Taken another two reported species (A. debilis and A. contorta) of subgenus Aristolochia into account, although genomic structure and size were highly conserved, the IR-SC boundary regions were variable between these nine cp genomes of Aristolochia (Figure 3). In general, contraction and expansion at the borders of IR regions are common evolutionary events and may cause IR size variation of plastomes [29,34-36]. The length of the IR regions of five Siphisia species, varying in the range of 25,664-25,700 bp, was longer than those of the four species of subgenus Aristolochia, which varied from 25,175 bp to 25,459 bp (Table 1) [28]. We identified three types of the IR-SC junctions from the nine Aristolochia species, according to the organization of genes (Figure 3). Within five detected species of subgenus Siphisia, its patterns were Type I and II, while the Type III only occurred in the four species of subgenus Aristolochia. Type I was found in A. mollissima, A. macrophylla, and A. kaempferi, and was characterized by $t r n H$ gene in IR region and LSC-IRb border located in rps19-trnH spacer. Type II was only found in A. moupinensis and A. kunmingensis and refers to LSC-IRb border within the rps19 gene. The $\operatorname{trnH}$ gene is intact and located upstream of $r p l 2$ in IRb region for type I and II. Type III pattern was found in the four species of subgenus Aristolochia, characterized by LSC-IRb and SSC-IRa border in the rps19-rpl2 spacer and $t r n H$ gene, respectively. The $t r n H$ gene spanned the junction between IR-LSC regions in the four species of subgenus Aristolochia.

The shift of IR-LSC borders, caused by contraction and expansion of the gene trnH, is one of major differences between the plastomes of the subgenera Siphisia and Aristolochia. The whole gene duplication of $t r n H$ was detected in most monocots (e.g., Acorus, Phalaenopsi and Dioscorea), D. granadensis (Winteraceae) of magnoliids, and basal eudicots (Ranunculus japonica and Ranunculus macranthus) [34,37-41]. Wang et al. (2008) conducted RT-PCR assays and deduced that the duplicated trnH genes in most of non-monocots and monocots were regulated by different expression levels of promoters, and had distinct fates [37]. Within the family Aristolochiaceae, the trnH gene was located in the LSC region of S. henryi, 128 bp away from the border of LSC-IR, and was also a single copy in the six cp genomes of Asarum, but not sure the positions of the gene [29]. Furthermore, the study proposed that the low-complexity $\operatorname{trnH}$ region and ultimately inversion of a portion of the LSC were due to an AAT repeat. For inversion of a large portion of the LSC region, there were genes rearranged 
in SC-IR borders of sequenced species of Asarum, the IR boundaries of cp genomes of Asarum were highly variable and experienced positional shifts at borders. Such as there was an entirety of the SSC of As. canadense and As. sieboldii has been incorporated into the IR, and the boundary of the LSC-IR was found within $r p l 2$ or rpl14 gene [29]. Within the species of $S$. henryi, rps19 pseudogene existed in the IRa region, with the length of $183 \mathrm{bp}$. The trnH-rps 19 gene cluster had been used to distinguish monocots from other angiosperm for the organization of gene flanking the IR-SC junction [37,39]. The events of contraction or expansion of the IR regions also can be used to distinguish the species within Aristolochiaceae.

\subsection{Inferring the Phylogeny and Species Identification of Aristolochia}

Chloroplast genomes provide abundant resources significant for evolutionary, taxonomic, and phylogenetic studies [42-44]. The whole cp genomes and protein-coding genes have been successfully used to resolve phylogenetic relationships at multiple taxonomic levels during the past decade $[45,46]$. Repeats can lead to changes in genomic structure, and can be investigated to population genetics of allied taxa [47-50]. Repeats in ten cp genomes revealed that the repeats had a great number, comprised of 38-80 repeats (Figure 5 and Table S4), 66 and 138 repeats were respectively detected in A. debilis and A. contorta [28]. Given the variability of these repeats between lineages, they can be informative regions for developing genomic markers for phylogenetic analysis. SSRs, known as microsatellites, are tandemly repeated DNA sequences that consist of one-six nucleotide repeat units and are ubiquitous throughout the genomes [51]. A total number of 95-142 SSRs were identified in the seven cp genomes detected (Figure 6 and Table S5). According to the analysis of high variable regions, the hotspot regions within seven $\mathrm{cp}$ genomes also provide sufficient information sites to reveal phylogeny structure among species of family Aristolochiaceae, especially for the spacer $y c f 1$ and $r p l 20$, with high nucleotide diversity and under positive selection (Table 4). The ycf1 gene could be served as the barcode of land plants, and was also recognized as the most variable regions in plastid genome $[50,52]$. The gene rpl20 is an important part of protein synthesis, and is involved in translation [53]. This study will also provide a reference for phylogenomic studies of closely related lineages among Aristolochia and other genera.

Furthermore, we can design effective markers for clarifying the phylogenetic relationships of Aristolochia and elucidating the evolutionary history of species complex of Aristolochia at the population level, based on the analysis of SSR and SNP sites. Understanding genetic variation within and between populations plays an important role in improving genetic diversity and is essential for future adaptive changes, reproduction patterns, and its conservation $[20,54,55]$. The cpDNA and B-class gene PISTILLATA (PI) have been used to investigate taxonomy at the species complex, such as Aristolochia kaempferi group, and these studies revealed that its DNA barcoding and taxonomy are difficult to assess for multiple hybridization and introgression events in the group [56,57]. More genes under selection and neutral markers should be used to clarify those multiple diversification events. It will better to apply the full genome information or hyper-variation regions to elucidate the species diversity of Aristolochia.

\section{Materials and Methods}

\subsection{Plant Material, DNA Extraction, and Sequencing}

We selected seven species according to their potential medicinal uses, including A. kaempferi, A. kunmingensis, A. macrophylla, A. mollissima, and A. moupinensis from subgenus Siphisia and A. tagala and A. tubiflora of subgenus Aristolochia (Table 7). Genomic DNA was isolated from silica-gel dried leaf tissue or herbarium specimens using Plant Genomic DNA Kit (TIANGEN, Beijing, China). DNA integrity was examined by electrophoresis in $1 \%(w / v)$ agarose gel and their concentration was measured using a NanoDrop spectrophotometer 2000 (Thermo Scientific; Waltham, MA, USA). The 
DNA was used to construct PE libraries with insert sizes of $150 \mathrm{bp}$ and sequenced according to the manufacturer's manual for the Illumina Hiseq X.

Table 7. Sampled species and their voucher specimens used in this study.

\begin{tabular}{cccc}
\hline Species & Samples & Voucher & locality \\
\hline A. kaempferi & E2265 & Yuan Wang & Japan, Tokyo \\
A. kunmingensis & E754 & Zhanghua Wang & China, Yunnan \\
A. macrophylla & E2111 & Jinshuang Ma & North America, North Carolia \\
A. mollissima & E1016 & Xinxin Zhu \& Zhixiang Hua & China, Guangdong \\
A. moupinensis & E1086 & Xinxin Zhu \& Zhixiang Hua & China, Sichuan \\
A. tagala & E1071 & Yuan Wang & China, Hongkong \\
A. tubiflora & E2239 & Shuwan Li & China, Guangxi \\
\hline
\end{tabular}

\subsection{Chloroplast Genome Assembly and Annotation}

We used the software Trimmomatic version 0.36 (Max Planck Institute of Molecular Plant Physiology, Potsdam, Germany) [58] to trim the low-quality reads. We retrieved the plastome sequence of $A$. contorta (NC_036152.1), A. debilis (NC_036153.1), Asarum costatum (AP018513.1), Asarum minamitanianum (AP018514.1), and Asarum sakawanum (AP017908.1) from GenBank and used these sequences as the references [28,30,31]. The plastome was assembled using mapping to reference genome and de novo methods as implemented in Geneious R11 (Biomatters, Auckland, New Zealand) [59].

The cp genomes of the seven species was annotated using the online program Dual Organellar GenoMe Annotator (DOGMA) (University of Texas at Austin, Austin, TX, USA) [60], Annotation of Organellar Genomes (GeSeq) [61] and Chloroplast Genome Annotation, Visualization, Analysis, and GenBank Submission (CPGAVAS) (Institute of Medicinal Plant Development, Chinese Academy of Medical Sciences and Peking Union Medical College, Beijing, China) [62]. The tRNA genes were confirmed using tRNAscan-SE software (v2.0, University of California, Santa Cruz, CA, USA) [63]. Plastome annotations were manually corrected with the software Artemis [64]. The gene map was drawn using the Organelle Genome DRAW (OGDRAW) [65,66] with default settings and checked manually. The complete cp genome sequences of the seven species were deposited in GenBank, accession numbers are MK503927-MG503933 (Table S6).

\subsection{Genome Structure Analyses}

The distribution of codon usage was investigated using the software CodonW (University of Texas, Houston, TX, USA) with the RSCU value [67]. GC content was analyzed using Molecular Evolutionary Genetics Analysis (MEGA v6.0, Tokyo Metropolitan University, Tokyo, Japan) [68]. REPuter program (https://bibiserv.cebitec.uni-bielefeld.de/reputer) (University of Bielefeld, Bielefeld, Germany) [69] was used to identify the size and location of repeat sequences, including forward, palindromic, reverse, and complement repeats in the seven cp genomes. For all repeat types, the minimal size was set as $30 \mathrm{bp}$ and the two repeat copies had at least $90 \%$ similarity. Perl script MISA (https://webblast.ipk-gatersleben.de/misa/) [70] was used to detect microsatellites (mono-, di-, tri-, tetra-, penta-, hexanucleotide repeats) with the following thresholds (unit size, min repeats): ten repeat units for mononucleotide SSRs, five repeat units for dinucleotide SSRs, four repeat units for trinucleotide SSRs, and three repeat units each for tetra-, penta-, and hexanucleotide SSRs.

\subsection{Positive Selection Analysis}

To identify the genes under selection, we scanned the cp genomes of seven species within Piperales using codeml of the package PAML4 [71,72]. The software was used for calculating the non-synonymous $(\mathrm{dN})$ and synonymous $(\mathrm{dS})$ substitution rates, along with their ratios $(\omega=\mathrm{dN} / \mathrm{dS})$. The analyses of selective pressures were conducted along the ML tree in Newick format (S7), which 
based on the whole CDS region was used to determine the phylogenetic relationships of these seven species. Each single-copy CDS sequences was aligned according to their amino acid sequence. We used the site-specific model with five site models (M0, M1a \& M2a, M7 \& M8) were employed to identify the signatures of adaptation across cp genomes. This model allowed the $\omega$ ratio to vary among sites, with a fixed $\omega$ ratio in all the branches. Comparing the site-specific model, M1a (nearly neutral) vs. M2a (positive selection) and M7 ( $\beta$ ) vs. M8 ( $\beta \& \omega)$ were calculated in order to detect positive selection [73]. Likelihood ratio test (LRT) of the comparison (M1a vs. M2a and M7 vs. M8) was used respectively to evaluate of the selection strength and the $p$ value of Chi square $\left(\chi^{2}\right)$ smaller than 0.05 is thought as significant. The Bayes Empirical Bayes (BEB) inference [74] was implemented in site models M2a and M8 to estimate the posterior probabilities and positive selection pressures of the selected genes.

\subsection{Genome Comparison and Nucleotide Variation Analysis}

The whole-genome (minus a copy of IR region) alignment for the cp genomes of the seven species including our A. moupinensis, A. kunmingensis, A. tubiflora and four reported species (A. contorta, As. canadense, S. henryi and P. cenocladum) of Piperales, was performed and plotted by the mVISTA program (http://genome.lbl.gov/vista/mvista/submit.shtml) in Shuffle-LAGAN model [75,76], and with $A$. moupinensis as the reference. The seven cp genomes of Aristolochia were first aligned using MAFFT v7 [77] and then manually adjusted using BioEdit v7.0.9 [78]. Variable sites and nucleotide variability across complete cp genomes, LSC, IR, SSC, and CDS regions of seven species were calculated using DnaSP v5 [79]. Furthermore, for the seven cp genomes minus a copy IR region, a sliding window analysis was conducted to evaluate the nucleotide variability using DnaSP software. The step size was set to 200 base pairs, and the window length was set to 600 base pairs.

\subsection{Phylogenetic Analyses}

To estimate phylogenetic relationships within the Aristolochiaceae, plastomes of 18 taxa were compared, including nine samples from Aristolochia, six and one cp genomes from Asarum and Saruma, respectively (Table S5). A total of $11 \mathrm{cp}$ genomes were downloaded from the NCBI database. In the phylogenetic analyses, P. auritum and P. cenocladum of Piper were used as outgroup. Phylogenetic trees were constructed by MP, ML and BI methods using the cp genomes, LSC, SSC, IR, CDS and hotspots regions. The sequences of the involved regions were aligned using MAFFT v7. MP analysis was performed with PAUP*4.0b10 [80], using a heuristic search performed 1000 replications and tree bisection-reconnection (TBR) branch swapping. BI was conducted using the program MrBayes v3.2 [81] with the GTR+I+G model at the CIPRES Science Gateway website (http://www.phylo.org/) [82]. The Markov Chain Monte Carlo (MCMC) analysis was run for 2,000,000 generations, sampling every 1000 generations. The posterior probabilities (PP) of the phylogeny and its branches were determined from the combined set of trees, discarding the first $25 \%$ trees of each run as burn-in, as determined by Tracer v1.7 [83]. Maximum likelihood phylogenies were constructed by a fast and effective stochastic algorithm using IQ-TREE v1.6.2 [84] with the Best-fit model by ModelFinder [85] according to Bayesian information criterion (BIC) and the robustness of the topology was estimated using 2000 bootstrap replicates. Figtree v1.4 (http:/ / tree.bio.ed.ac.uk/software/figtree/) [86] was used to visualize and annotate trees.

\section{Conclusions}

The complete cp genomes of A. kaempferi, A. kunmingensis, A. macrophylla, A. mollissima, and A. moupinensis of the subgenus Siphisia, and A. tagala and A. tubiflora of the subgenus Aristolochia were reported in this study. The cp genomes length and gene content of the genus Aristolochia were comparatively conserved. Although genomic structure and size were highly conserved, the IR-SC boundary regions were variable between these nine cp genomes of Aristolochia. The whole duplicated trnH gene within five species of Siphisia is one of major differences between the plastomes of the subgenera Siphisia and Aristolochia. We also identified SSR sites, five positive selection sites and 16 
variable regions, which provide a reference for developing tools to further study Aristolochia species. Furthermore, the phylogenetic constructions with six datasets of $18 \mathrm{cp}$ genomes illustrated robust and consistent relationships with high supports.

Supplementary Materials: Supplementary materials can be found at http:/ /www.mdpi.com/xxx/s1.

Author Contributions: X.L. performed the experiments, analyzed the data, and wrote the manuscript; Y.Z. assembled sequences and revised the manuscript; X.Z. and S.L. collected, identified plant materials and gave suggestions to the manuscript; J.M. revised the manuscript. All authors have read and approved the final manuscript.

Funding: This work was supported by the National Natural Science Foundation of China (No. 31370225).

Acknowledgments: The authors give special thanks to Shuwan Li, Yuan Wang, Zhanghua Wang, and Zhixiang Hua for collecting plant material. We acknowledged someone for their assistance with fieldwork, for data analysis, for giving comments on the manuscript paper. Our sincere thanks are also to the anonymous reviewers for their comments and suggestions.

Conflicts of Interest: The authors declare no conflict of interest.

\section{Abbreviations}

$\begin{array}{ll}\text { RSCU } & \text { Relative synonymous codon usage } \\ \text { NGS } & \text { Next-generation sequencing } \\ \text { TLA } & \text { Three letter acronym } \\ \text { SSR } & \text { Simple sequence repeats } \\ \text { ATP } & \text { Adenosine triphosphate } \\ \text { MP } & \text { Maximum parsimony } \\ \text { ML } & \text { Maximum likelihood } \\ \text { Pi } & \text { Nucleotide diversity } \\ \text { BI } & \text { Bayesian Inference } \\ \text { AAs } & \text { Aristolochic acids } \\ \text { LSC } & \text { Large single copy } \\ \text { SSC } & \text { Small single copy } \\ \text { CDS } & \text { Coding sequence } \\ \text { IR } & \text { Inverted repeat } \\ \text { SC } & \text { Single copy } \\ \text { CP } & \text { Chloroplast }\end{array}$

\section{References}

1. Neinhuis, C.; Wanke, S.; Hilu, K.W.; Müller, K.; Borsch, T. Phylogeny of Aristolochiaceae based on parsimony, likelihood, and Bayesian analyses of trnL-trnF sequences. Plant Syst. Evol. 2005, 250, 7-26. [CrossRef]

2. Wagner, S.T.; Isnard, S.; Rowe, N.P.; Samain, M.S.; Neinhuis, C.; Wanke, S. Escaping the lianoid habit: Evolution of shrub-like growth forms in Aristolochia subgenus Isotrema (Aristolochiaceae). Am. J. Bot. 2012, 99, 1609-1629. [CrossRef] [PubMed]

3. Feng, Y.X.; Lin, S.Q.; Zhang, X.Q. Botanical and pharmacognostical studies of Chinese Aristolochia: Resource utilization. Acta Pharm. Sin. 1983, 18, 291-298.

4. Ma, J.S. Medicinal resources of Aristolochia in China. Chin. Wild Plant Resour. 1988, 3, 31-34.

5. Chen, C.H.; Dickman, K.G.; Moriya, M.; Zavadil, J.; Sidorenko, V.S.; Edwards, K.L.; Gnatenkod, D.V.; Wu, L.; Turesky, R.J.; Wu, X.R.; et al. Aristolochic acid-associated urothelial cancer in Taiwan. Proc. Natl. Acad. Sci. USA 2012, 109, 8241-8246. [CrossRef] [PubMed]

6. Wu, L.; Sun, W.; Wang, B.; Zhao, H.; Li, Y.; Cai, S.; Li, X.; Zhu, Y.J.; Yao, H.; Song, J.Y.; et al. An integrated system for identifying the hidden assassins in traditional medicines containing aristolochic acids. Sci. Rep. 2015, 5, 11318. [CrossRef] [PubMed]

7. Tsai, D.M.; Kang, J.J.; Lee, S.S.; Wang, S.Y.; Tsai, I.; Chen, G.Y.; Liao, H.W.; Chu, L.W.; Kuo, C.H.; Tseng, Y.J. Metabolomic analysis of complex Chinese remedies: Examples of induced nephrotoxicity in the mouse from a series of remedies containing aristolochic acid. Evid.-Based Complement. Altern. Med. 2013, 2013, 263757. [CrossRef] [PubMed] 
8. Ng, A.W.T.; Poon, S.L.; Huang, M.N.; Lim, J.Q.; Boot, A.; Yu, W.; Suzuki, Y.; Thangaraju, S.; Ng, C.C.Y.; Tan, P.; et al. Aristolochic acids and their derivatives are widely implicated in liver cancers in Taiwan and throughout Asia. Sci. Transl. Med. 2017, 9, eaan6446. [CrossRef] [PubMed]

9. Martena, M.J.; Van der Wielen, J.C.A.; Van de Laak, L.F.J.; Konings, E.J.M.; de Groot, H.N.; Rietjens, I.M.C.M. Enforcement of the ban on aristolochic acids in chinese traditional herbal preparations on the dutch market. Anal. Bioanal. Chem. 2007, 389, 263-275. [CrossRef] [PubMed]

10. Lawrence, M.K.; González, F.A. Phylogenetic Relationships in Aristolochiaceae. Syst. Bot. 2003, 28 , $236-249$. [CrossRef]

11. Wanke, S.; Jaramillo, M.A.; Borsch, T.; Samain, M.S.; Quandt, D.; Neinhuis, C. Evolution of Piperales-matK gene and trnK intron sequence data reveal lineage specific resolution contrast. Mol. Phylogenet. Evol. 2007, 42, 477-497. [CrossRef] [PubMed]

12. Lawrence, M.K. A cladistic analysis of Asarum and implications for the evolution of Herkogamy. Am. J. Bot. 1997, 84, 1752-1765.

13. Lawrence, M.K. Phylogenetic relationships in Asarum (Aristolochiaceae) based on morphology and ITS sequences. Am. J. Bot. 1998, 85, 1454-1467.

14. González, F.A.; Stevenson, D.W. A phylogenetic analysis of the subfamily Aristolochioideae (Aristolochiaceae). Rev. Acad. Colomb. Cienc. 2002, 66, 59-65.

15. Ohi-Toma, T.; Sugawara, T.; Neihuis, C.; Murata, H.; Wanke, S.; Murata, J. Molecular phylogeny of Aristolochia sensu lato(Aristolochiaceae) based on sequences of $r b c L$, mat $K$, and $p h y A$ genes, with special reference to differentiation of chromosome numbers. Syst. Bot. 2006, 31, 481-492. [CrossRef]

16. Wanke, S.; Samain, M.S.; Vanderschaeve, L.; Mathieu, G.; Goetghebeur, P.; Neinhuis, C. Phylogeny of the genus Peperomia (Piperaceae) inferred from the trnK/matK region (cpDNA). Plant Biol. 2006, 8, 93-102. [CrossRef] [PubMed]

17. González, F.; Wagner, S.T.; Salomo, K.; Symmank, L.; Samain, M.-S.; Isnard, S.; Rowe, N.P.; Neinhuis, C.; Wanke, S.; Carine, M. Present trans-Pacific disjunct distribution of Aristolochia subgenus Isotrema (Aristolochiaceae) was shaped by dispersal, vicariance and extinction. J. Biogeogr. 2014, 41, 380-391. [CrossRef]

18. Dechbumroong, P.; Aumnouypol, S.; Denduangboripant, J.; Sukrong, S. DNA barcoding of Aristolochia plants and development of species-specific multiplex PCR to aid HPTLC in ascertainment of Aristolochia herbal materials. PLoS ONE 2018, 13, e0202625. [CrossRef] [PubMed]

19. Sarma, B.; Tanti, B. Analysis of genetic diversity of certain species of Aristolochia using ISSR-based molecular markers. Curr. Life Sci. 2017, 3, 47-53. [CrossRef]

20. Yang, Z.Y.; Yi, T.S.; Zeng, L.Q.; Gong, X. The population genetic structure and diversification of Aristolochia delavayi (Aristolochiaceae), an endangered species of the dry hot valleys of the Jinsha River, southwestern China. Botany 2014, 92, 579-587. [CrossRef]

21. Douglas, S.E. Plastid evolution: Origins, diversity, trends. Curr. Opin. Genet. Dev. 1998, 8, 655-661. [CrossRef]

22. Moore, M.J.; Bell, C.D.; Soltis, P.S.; Soltis, D.E. Using plastid genome-scale data to resolve enigmatic relationships among basal angiosperms. Proc. Natl. Am. Sci. USA 2007, 104, 19363-19368. [CrossRef] [PubMed]

23. Yang, J.B.; Yang, S.X.; Li, H.T.; Jing, Y.; Li, D.Z. Comparative chloroplast genomes of Camellia species. PLoS ONE 2013, 8, e73053. [CrossRef] [PubMed]

24. Huang, H.; Shi, C.; Liu, Y.; Mao, S.; Gao, L. Thirteen Camellia chloroplast genome sequences determined by high-throughput sequencing: Genome structure and phylogenetic relationships. BMC Evol. Boil. 2014, 14, 151. [CrossRef] [PubMed]

25. Lei, W.; Ni, D.; Wang, Y.; Shao, J.; Wang, X.; Yang, D.; Wang, J.S.; Chen, H.M.; Liu, C. Intraspecific and heteroplasmic variations, gene losses and inversions in the chloroplast genome of Astragalus Membranaceus. Sci. Rep. 2016, 6, 21669. [CrossRef] [PubMed]

26. Jansen, R.K.; Raubeson, L.A.; Boore, J.L.; Depamphilis, C.W.; Chumley, T.W.; Haberle, R.C. Methods for obtaining and analyzing whole chloroplast genome sequences. Methods Enzymol. 2005, 395, 348-384. [PubMed]

27. Wicke, S.; Schneeweiss, G.M.; Depamphilis, C.W.; Müller, K.F.; Quandt, D. The evolution of the plastid chromosome in land plants: Gene content, gene order, gene function. Plant Mol. Biol. 2011, 76, $273-297$. [CrossRef] [PubMed] 
28. Zhou, J.G.; Chen, X.L.; Cui, Y.X.; Sun, W.; Li, Y.H.; Wang, Y.; Song, J.Y.; Yao, H. Molecular Structure and Phylogenetic Analyses of Complete Chloroplast Genomes of Two Aristolochia Medicinal Species. Int. J. Mol. Sci. 2017, 18, 1839. [CrossRef] [PubMed]

29. Sinn, B.T.; Sedmak, D.D.; Kelly, L.M.; Freudenstein, J.V. Total duplication of the small single copy region in the angiosperm plastome: Rearrangement and inverted repeat instability in Asarum. Am. J. Bot. 2018, 105, 71-84. [CrossRef] [PubMed]

30. Takahashi, D.; Sakaguchi, S.; Isagi, Y.; Setoguchi, H. Comparative chloroplast genomics of series Sakawanum in genus Asarum (Aristolochiaceae) to develop single nucleotide polymorphisms (SNPs) and simple sequence repeat (SSR) markers. J. For. Res. 2018, 23, 387-392. [CrossRef]

31. Sakaguchi, S.; Ueno, S.; Tsumura, Y. Application of a simplified method of chloroplast enrichment to small amounts of tissue for chloroplast genome sequencing. Appl. Plant Sci. 2017, 5, 1700002. [CrossRef] [PubMed]

32. NCBI. Genome. Available online: https://www.ncbi.nlm.nih.gov/ (accessed on 14 January 2019).

33. Xu, J.W.; Feng, D.J.; Song, G.S.; Wei, X.L.; Chen, L.; Wu, X.L.; Li, X.G.; Zhu, Z. The first intron of rice epsp synthase enhances expression of foreign gene. Sci. China Life Sci. 2003, 46, 561-569. [CrossRef] [PubMed]

34. Raubeson, L.A.; Peery, R.; Chumley, T.W.; Dziubek, C.; Fourcade, H.M.; Boore, J.L.; Jansen, R.K. Comparative chloroplast genomics: Analyses including new sequences from the angiosperms Nuphar advena and Ranunculus Macranthus. BMC Genom. 2007, 8, 174. [CrossRef] [PubMed]

35. Yang, M.; Zhang, X.; Liu, G.; Yin, Y.; Chen, K.; Yun, Q.; Zhao, D.J.; Al-Mssallem, I.S.; Yu, J. The complete chloroplast genome sequence of date palm (Phoenix dactylifera L.). PLoS ONE 2010, 5, e12762. [CrossRef] [PubMed]

36. Kim, K.J.; Lee, H.L. Complete chloroplast genome sequences from Korean Ginseng (Panax schinseng Nees) and comparative analysis of sequence evolution among 17 vascular plants. DNA Res. 2004, 11, 247-261. [CrossRef] [PubMed]

37. Wang, R.J.; Cheng, C.L.; Chang, C.C.; Wu, C.L.; Su, T.M.; Chaw, S.M. Dynamics and evolution of the inverted repeat-large single copy junctions in the chloroplast genomes of monocots. BMC Evol. Boil. 2008, 8, 36. [CrossRef] [PubMed]

38. Huotari, T.; Korpelainen, H. Complete chloroplast genome sequence of Elodea canadensis and comparative analyses with other monocot plastid genomes. Gene 2012, 508, 96-105. [CrossRef] [PubMed]

39. Luo, Y.; Ma, P.F.; Li, H.T.; Yang, J.B.; Wang, H.; Li, D.Z. Plastid phylogenomic analyses resolve Tofieldiaceae as the root of the early diverging monocot order Alismatales. Genome Biol. Evol. 2016, 8, 932-945. [CrossRef] [PubMed]

40. Cai, Z.Q.; Penaflor, C.; Kuehl, J.V.; Leebens-Mack, J.; Carlson, J.E.; Pamphilis, C.W.D.; Boore, J.L.; Jansen, R.K. Complete plastid genome sequences of Drimys, Liriodendron, and Piper: Implications for the phylogenetic relationships of magnoliids. BMC Evol. Boil. 2006, 6, 77. [CrossRef]

41. Chang, C.C.; Lin, H.C.; Lin, I.; Chow, T.Y.; Chen, H.H.; Chen, W.H.; Cheng, C.H.; Lin, C.Y.; Liu, S.M.; Chang, C.C.; et al. The chloroplast genome of Phalaenopsis aphrodite (Orchidaceae): Comparative analysis of evolutionary rate with that of grasses and its phylogenetic implications. Mol. Biol. Evol. 2006, 23, 279-291. [CrossRef] [PubMed]

42. Borsch, T.; Quandt, D. Mutational dynamics and phylogenetic utility of noncoding chloroplast DNA. Plant Syst. Evol. 2009, 282, 169-199. [CrossRef]

43. Dong, W.P.; Liu, J.; Yu, J.; Wang, L.; Zhou, S.L. Highly variable chloroplast markers for evaluating plant phylogeny at low taxonomic levels and for DNA barcoding. PLoS ONE 2012, 7, e35071. [CrossRef] [PubMed]

44. Tong, W.; Kim, T.S.; Park, Y.J. Rice chloroplast genome variation architecture and phylogenetic dissection in diverse Oryza species assessed by whole-genome resequencing. Rice 2016, 9, 57. [CrossRef] [PubMed]

45. Dong, W.P.; Liu, H.; Xu, C.; Zuo, Y.J.; Chen, Z.J.; Zhou, S.L. A chloroplast genomic strategy for designing taxon specific DNA mini-barcodes: A case study on ginsengs. BMC Genet. 2014, 15, 138. [CrossRef] [PubMed]

46. Du, Y.P.; Bi, Y.; Yang, F.P.; Zhang, M.F.; Chen, X.Q.; Xue, J.; Zhang, X.H. Complete chloroplast genome sequences of Lilium: Insights into evolutionary dynamics and phylogenetic analyses. Sci. Rep. 2017, 7, 5751. [CrossRef] [PubMed]

47. Timme, R.E.; Kuehl, J.V.; Boore, J.L.; Jansen, R.K. A comparative analysis of the Lactuca and Helianthus (Asteraceae) plastid genomes: Identification of divergent regions and categorization of shared repeats. Am. J. Bot. 2007, 94, 302-312. [CrossRef] [PubMed] 
48. Nie, X.J.; Lv, S.Z.; Zhang, Y.X.; Du, X.H.; Wang, L.; Biradar, S.S.; Tan, X.F.; Wan, F.H.; Song, W.N. Complete chloroplast genome sequence of a major invasive species, crofton weed (Ageratina adenophora). PLoS ONE 2012, 7, e36869. [CrossRef] [PubMed]

49. Huang, J.; Chen, R.H.; Li, X.G. Comparative analysis of the complete chloroplast genome of four known Ziziphus species. Genes 2017, 8, 340. [CrossRef] [PubMed]

50. Gu, C.H.; Tembrock, L.R.; Zheng, S.Y.; Wu, Z.Q. The complete chloroplast genome of Catha edulis: A comparative analysis of genome features with related species. Int. J. Mol. Sci. 2018, 19, 525. [CrossRef] [PubMed]

51. Powell, W.; Morgante, M.; Mcdevitt, R.; Vendramin, G.G.; Rafalski, J.A. Polymorphic simple sequence repeat regions in chloroplast genomes: Applications to the population genetics of pines. Proc. Natl. Acad. Sci. USA 1995, 92, 7759-7763. [CrossRef] [PubMed]

52. Dong, W.P.; Xu, C.; Li, C.H.; Sun, J.H.; Zuo, Y.J.; Shi, S.; Cheng, T.; Guo, J.J.; Zhou, S.L. ycf1, the most promising plastid DNA barcode of land plants. Sci. Rep. 2015, 5, 8348. [CrossRef] [PubMed]

53. Muto, A.; Ushida, C. Transcription and translation. Methods Cell Biol. 1995, 48, 483.

54. Koren, O.G.; Nakonechnaya, O.V.; Zhuravlev, Y.N. Genetic structure of natural populations of the relict species Aristolochia manshuriensis (Aristolochiaceae) in disturbed and intact habitats. Russ. J. Genet. 2009, 45, 678-684. [CrossRef]

55. Nakonechnaya, O.V.; Kholina, A.B.; Koren, O.G.; Zhuravlev, Y.N. Genetic diversity of a rare species Aristolochia contorta Bunge (Aristolochiaceae) in Primorsky krai. Russ. J. Genet. 2012, 48, 152-162. [CrossRef]

56. Watanabe, K.; Kajita, T.; Murata, J. Chloroplast DNA and variation and geographical structure of the Aristolochia kaempferi group (Aristolochiaceae). Am. J. Bot. 2006, 93, 442-453. [CrossRef] [PubMed]

57. Watanabe, K.; Ohi-Toma, T.; Murata, J. Multiple hybridization in the Aristolochia kaempferi group (Aristolochiaceae): Evidence from reproductive isolation and molecular phylogeny. Am. J. Bot. 2008, 95, 885-896. [CrossRef] [PubMed]

58. Bolger, A.; Lohse, M.; Usadel, B. Trimmomatic: A flexible trimmer for Illumina sequence data. Bioinformatics 2014, 30, 2114-2120. [CrossRef] [PubMed]

59. Drummond, A.J.; Ashton, B.; Buxton, S.; Cheung, M.; Cooper, A.; Duran, C.; Field, M. Geneious; Version 5.3+; Biomatters: Auckland, New Zealand, 2011.

60. Wyman, S.K.; Jansen, R.K.; Boore, J.L. Automatic annotation of organelle genomes with DOGMA. Bioinformatics 2004, 20, 3252-3255. [CrossRef] [PubMed]

61. Tillich, M.; Lehwark, P.; Pellizzer, T.; Ulbrichtjones, E.S.; Fischer, A.; Bock, R.; Greiner, S. Geseq-Versatile and accurate annotation of organelle genomes. Nucleic Acids Res. 2017, 45, W6-W11. [CrossRef] [PubMed]

62. Liu, C.; Shi, L.C.; Zhu, Y.; Chen, H.M.; Zhang, J.H.; Lin, X.H.; Guan, X.J. CpGAVAS, an integrated web server for the annotation, visualization, analysis, and GenBank submission of completely sequenced chloroplast genome sequences. BMC Genom. 2012, 13, 715. [CrossRef] [PubMed]

63. Schattner, P.; Brooks, A.N.; Lowe, T.M. The tRNAscan-SE, snoscan and snoGPS web servers for the detection of tRNAs and snoRNAs. Nucleic Acids Res. 2005, 33, W686-W689. [CrossRef] [PubMed]

64. Carver, T.; Harris, S.R.; Berriman, M.; Parkhill, J.; Mcquillan, J.A. Artemis: An integrated platform for visualization and analysis of high-throughput sequence-based experimental data. Bioinformatics 2012, 28, 464-469. [CrossRef] [PubMed]

65. Lohse, M.; Drechsel, O.; Bock, R. Organellargenomedraw (OGDRAW): A tool for the easy generation of high-quality custom graphical maps of plastid and mitochondrial genomes. Curr. Genet. 2007, 52, 267-274. [CrossRef] [PubMed]

66. Lohse, M.; Drechsel, O.; Kahlau, S.; Bock, R. OrganellarGenomeDRAW-A suite of tools for generating physical maps of plastid and mitochondrial genomes and visualizing expression data sets. Nucleic Acids Res. 2013, 41, W575-W581. [CrossRef] [PubMed]

67. Sharp, P.M.; Li, W.H. The codon adaptation index-A measure of directional synonymous codon usage bias, and its potential applications. Nucleic Acids Res. 1987, 15, 1281-1295. [CrossRef] [PubMed]

68. Koichiro, T.; Glen, S.; Daniel, P.; Alan, F.; Sudhir, K. MEGA6: Molecular Evolutionary Genetics Analysis Version 6.0. Mol. Biol. Evol. 2013, 30, 2725-2729.

69. Kurtz, S.; Choudhuri, J.V.; Ohlebusch, E.; Schleiermacher, C.; Stoye, J.; Giegerich, R. Reputer: The manifold applications of repeat analysis on a genomic scale. Nucleic Acids Res. 2001, 29, 4633-4642. [CrossRef] [PubMed] 
70. Thiel, T.; Michalek, W.; Varshney, R.K.; Graner, A. Exploiting EST databases for the development and characterization of gene-derived SSR-markers in barley (Hordeum vulgare L.). Theor. Appl. Genet. 2003, 106, 411-422. [CrossRef] [PubMed]

71. Yang, Z. PAML: A program package for phylogenetic analysis by maximum likelihood. Bioinformatics 1997, 13, 555-556. [CrossRef]

72. Yang, Z. PAML 4: Phylogenetic analysis by maximum likelihood. Mol. Biol. Evol. 2007, 24, $1586-1591$. [CrossRef] [PubMed]

73. Yang, Z.; Nielsen, R. Codon-substitution models for detecting molecular adaptation at individual sites along specific lineages. Mol. Biol. Evol. 2002, 19, 908-917. [CrossRef] [PubMed]

74. Yang, Z.; Wong, W.S.W.; Nielsen, R. Bayes empirical bayes inference of amino acid sites under positive selection. Mol. Biol. Evol. 2005, 22, 1107-1118. [CrossRef] [PubMed]

75. Brudno, M.; Malde, S.; Poliakov, A.; Do, C.B.; Couronne, O.; Dubchak, I.; Batzoglou, S. Glocal alignment: Finding rearrangements during alignment. Bioinformatics 2003, 19, i54-i62. [CrossRef] [PubMed]

76. Frazer, K.A.; Pachter, L.; Poliakov, A.; Rubin, E.M.; Dubchak, I. Vista: Computational tools for comparative genomics. Nucleic Acids Res. 2004, 32, w273-w279. [CrossRef] [PubMed]

77. Katoh, K.; Misawa, K.; Kuma, K.; Miyata, T. MAFFT: A novel method for rapid multiple sequence alignment based on fast fourier transform. Nucleic Acids Res. 2002, 30, 3059-3066. [CrossRef] [PubMed]

78. Hall, T.A. Bioedit: A user-friendly biological sequence alignment editor and analysis program for windows 95/98/NT. Nucleic Acids Symp. Ser. 1999, 41, 95-98.

79. Rozas, J.; Sánchez-DelBarrio, J.C.; Messeguer, X.; Rozas, R. Dnasp, dna polymorphism analyses by the coalescent and other methods. Bioinformatics 2003, 19, 2496-2497. [CrossRef] [PubMed]

80. Swofford, D.L. PAUP*: Phylogenetic Analysis Using Parsimony, Distance, and Likelihood; Version 4; Sinauer: Sunderland, MA, USA, 2002.

81. Ronquist, F.; Teslenko, M.; Van Der Mark, P.; Ayres, D.L.; Darling, A.; Höhna, S.; Larget, B.; Liu, L.; Suchard, M.A.; Huelsenbeck, J.P. MrBayes 3.2: Efficient Bayesian phylogenetic inference and model choice across a large model space. Syst. Biol. 2012, 61, 539-542. [CrossRef] [PubMed]

82. Miller, M.A.; Pfeiffer, W.; Schwartz, T. Creating the CIPRES Science Gateway for inference of large phylogenetic trees. GCE 2010, 14, 1-8.

83. Rambaut, A.; Drummond, A.J.; Xie, D.; Baele, G.; Suchard, M.A. Posterior summarization in bayesian phylogenetics using Tracer 1.7. Syst. Biol. 2018, 10, 901-904. [CrossRef] [PubMed]

84. Nguyen, L.T.; Schmidt, H.A.; Von Haeseler, A.; Minh, B.Q. IQ-tree: A fast and effective stochastic algorithm for estimating maximum-likelihood phylogenies. Mol. Biol. Evol. 2015, 32, 268-274. [CrossRef] [PubMed]

85. Kalyaanamoorthy, S.; Bui, M.Q.; Wong, T.K.F.; Von Haeseler, A.; Jermiin, L.S. ModelFinder: Fast model selection for accurate phylogenetic estimates. Nat. Methods 2017, 14, 587-589. [CrossRef] [PubMed]

86. Figtree v1.4. Available online: http://tree.bio.ed.ac.uk/software/figtree/ (accessed on 14 January 2019). 